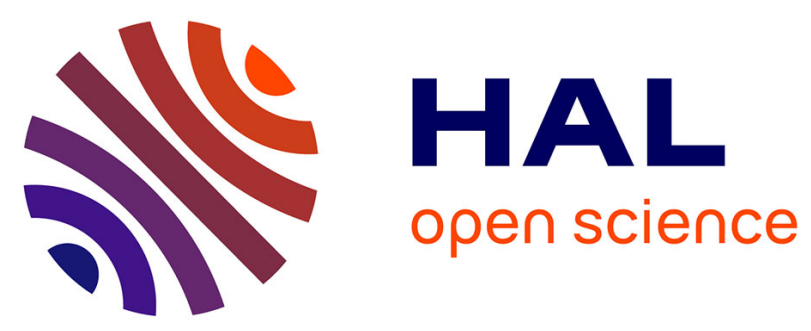

\title{
Structural analysis of natural killer cell receptor protein 1 (NKR-P1) extracellular domains suggests a conserved long loop region involved in ligand specificity
}

Žofie Sovová, Vladimír Kopecký, Tomáš Pazderka, Kateřina Hofbauerová, Daniel Rozbeský, Ondřej Vaněk, Karel Bezouška, Rüdiger Ettrich

\section{To cite this version:}

Žofie Sovová, Vladimír Kopecký, Tomáš Pazderka, Kateřina Hofbauerová, Daniel Rozbeský, et al.. Structural analysis of natural killer cell receptor protein 1 (NKR-P1) extracellular domains suggests a conserved long loop region involved in ligand specificity. Journal of Molecular Modeling, 2010, 17 (6), pp.1353-1370. 10.1007/s00894-010-0837-y · hal-00623308

\section{HAL Id: hal-00623308 https://hal.science/hal-00623308}

Submitted on 14 Sep 2011

HAL is a multi-disciplinary open access archive for the deposit and dissemination of scientific research documents, whether they are published or not. The documents may come from teaching and research institutions in France or abroad, or from public or private research centers.
L'archive ouverte pluridisciplinaire HAL, est destinée au dépôt et à la diffusion de documents scientifiques de niveau recherche, publiés ou non, émanant des établissements d'enseignement et de recherche français ou étrangers, des laboratoires publics ou privés. 


\title{
Structural analysis of natural killer cell receptor protein 1 (NKR- P1) extracellular domains suggests a conserved long loop region involved in ligand specificity
}

Received: 18.07.2010 / Accepted: 24.08.2010

Žofie Sovová ${ }^{1.2}$, Vladimír Kopecký Jr. ${ }^{3}$, Tomáš Pazderka ${ }^{3}$, Kateřina Hofbauerová ${ }^{3,4}$ Daniel Rozbeský ${ }^{4,5}$, Ondřej Vaněk ${ }^{4,5}$, Karel Bezouška ${ }^{4,5}$, Rüdiger Ettrich ${ }^{1,2, 凶}$

${ }^{1}$ Laboratory of Structural Biology, Institute of Systems Biology and Ecology, Academy of Sciences of the Czech Republic, Zámek 136, 37333 Nové Hrady, Czech Republic

${ }^{2}$ Faculty of Sciences, University of South Bohemia, Zámek 136, 37333 Nové Hrady, Czech Republic

${ }^{3}$ Institute of Physics, Faculty of Mathematics and Physics, Charles University in Prague, Ke Karlovu 5, 12116 Prague 2, Czech Republic

${ }^{4}$ Institute of Microbiology, Academy of Sciences of the Czech Republic, Vídeňská 1083, 14220 Prague 4, Czech Republic

${ }^{5}$ Department of Biochemistry, Faculty of Science, Charles University in Prague, Albertov 2030, 12840 Prague 2, Czech Republic

${ }^{\circledR}$ Tel: +420-386 361 297, Fax: +420-386 361 279; E-mail: ettrich@nh.usbe.cas.cz

\begin{abstract}
Receptor proteins at the cell surface regulate the ability of natural killer cells to recognize and kill a variety of aberrant target cells. The structural features determining the function of natural killer receptor proteins 1 (NKR-P1s) are largely unknown. In the present work, refined homology models are generated for the C-type lectin-like extracellular domains of rat NKRP1A and NKR-P1B, mouse NKR-P1A, NKR-P1C, NKR-P1F, and NKR-P1G, and human NKR-P1 receptors. Experimental data on secondary structure, tertiary interactions, and thermal transitions are acquired for four of the proteins using Raman and infrared spectroscopy. The experimental and modeling results are in agreement with respect to the overall structures of the NKR-P1 receptor domains, while suggesting functionally significant
\end{abstract}


local differences among species and isoforms. Two sequence regions that are conserved in all analyzed NKR-P1 receptors do not correspond to conserved structural elements as might be expected, but are represented by loop regions, one of which is arranged differently in the constructed models. This region displays high flexibility but is anchored by conserved sequences, suggesting that its position relative to the rest of the domain might be variable. This loop may contribute to ligand-binding specificity via a coupled conformational transition.

Keywords Molecular dynamics - Two-dimensional correlation analysis - Differential scanning calorimetry $\cdot$ Thermal dynamics $\cdot$ Raman Spectroscopy $\cdot$ FTIR $\cdot$ Topology $\cdot$ RMSF $\cdot$ Cladogram 


\section{Introduction}

Natural killer (NK) cells are large granular lymphocytes able to recognize and kill a large variety of target cells and to regulate the reactions at the interface of innate and adaptive immunity through secretion of lymphokines and by direct killing $[1,2]$. The cytotoxic activity of NK cells is tightly regulated via activating and inhibiting cell-surface receptors, one group of them being the NK cell lectin-like receptor proteins, one subtype of which are the NKR$\mathrm{P} 1 \mathrm{~s}$. The NKR-P1s are transmembrane glycoproteins classified as type II due to their external C-terminus, with an extracellular C-type lectin-like domain (CTLD) and a short cytoplasmic domain. To initiate the NK cell response, activating NK cell receptors recognize a diverse range of ligands including cytokines, antibody $\mathrm{Fc}$ domains and other proteins and saccharides presented by target cells. Inhibitory NK cell receptors recognize MHC class I molecules and other proteins serving as a marker of cell health. Tumor, virally infected, stressed or otherwise damaged cells that can resist $\mathrm{T}$ cell mediated immunity because of the low levels of these markers expressed at their surface are no longer protected by their inhibitory signals and this may lead to NK cell activation and an elimination of the target cells [3]. Functions of NKR-P1s were enigmatic until their ligands were found to be closely related family of Clr lectin-like receptors [2]. Despite NKR-P1 family include both activating and inhibitory receptors, the CTLDs of NKR-P1 family members share considerable homology; thus the structural origins of ligand-binding specificity are of interest. In the present work, multiple sequence alignment, protein homology modeling, and molecular dynamics simulations are combined with protein expression, vibrational spectroscopy, and thermal analysis to examine evolutionary and structural divergences within the family of NKR-P1 receptor CTLDs.

\section{Methods}

\section{Protein preparation}

DNA coding for the extracellular part of mNKR-P1A/C proteins (mNKR-P1A/C; to specify the origin of the receptor, the first letter of each organism name is used prior to the receptor name, i.e., $\mathrm{m}$ for mouse, $\mathrm{r}$ for rat, etc.), was amplified from the total mRNA isolated from the spleen of C57BL/6 mouse and subcloned into expression vector pET-30a (Novagen). 
Expression plasmids were transformed into Escherichia coli BL-21 (DE3) Gold (Stratagene). Bacteria were grown in LB medium, induction was performed with $0.1 \mathrm{mM}$ isopropyl- $\beta-\mathrm{D}-$ thiogalactopyranoside and the induced culture was grown for $2 \mathrm{~h}$. Proteins were refolded from inclusion bodies and were purified by HPLC ion exchange and gel filtration chromatography. The protein samples for experiments were concentrated at $10.4 \mathrm{mg} / \mathrm{mL}$ in a $15 \mathrm{mM}$ Tris- $\mathrm{HCl}$ buffer with $150 \mathrm{mM} \mathrm{NaCl}, \mathrm{pH} 8.0$.

The rNKR-P1A/B proteins were prepared as described previously [4]. Proteins were dissolved in a $10 \mathrm{mM}$ Tris- $\mathrm{HCl}$ buffer with $50 \mathrm{mM} \mathrm{NaCl}, \mathrm{pH} 7.4$, in concentrations of $9.1 \mathrm{mg} / \mathrm{mL}$ and $3.8 \mathrm{mg} / \mathrm{mL}$, respectively. The concentrations were determined by Bradford assay [5].

\section{Raman spectroscopy}

Raman spectra of aqueous solutions of mNKR-P1A/C proteins were recorded in a standard $90^{\circ}$ geometry on a multichannel instrument based on Spex 270M single spectrograph with 1800 grooves/mm grating (Jobin-Yvon), a holographic notch-plus filter (Kaiser Optical Systems) and a liquid nitrogen cooled CCD detection system (Princeton Instruments) measuring 1340 pixels along the dispersion axis. The spectral resolution was approximately $5 \mathrm{~cm}^{-1}$. Samples in a capillary micro-cell ( $5 \mu \mathrm{L}$ inner volume) were excited with a $532.2 \mathrm{~nm}$ line (300 $\mathrm{mW}$ of radiant power per sample) NdYAG Verdi 2 laser (Coherent) and kept at $4{ }^{\circ} \mathrm{C}$ during all experiments using an external water bath (Neslab). The acquisition time for the spectra was 60 minutes. The spectra of temperature dependence each consisted of $5 \mathrm{~min}$ exposures. Temperatures in the $5-90{ }^{\circ} \mathrm{C}$ region were adjusted with $5{ }^{\circ} \mathrm{C}$ increments using the external water bath (Neslab) and equilibrated for 4 minutes before measurement. The wavenumber scale was calibrated with neon glow-lamp lines. Therefore, Raman frequencies of well-resolved bands are accurate to $\pm 0.5 \mathrm{~cm}^{-1}$.

The solutions of rNKR-P1A/B proteins were excited with a $514.5 \mathrm{~nm}$ Ar-ion laser Innova 300 (Coherent) using the same Raman spectrometer with the same experimental setup. Both spectra were accumulated for $600 \mathrm{~min}$ to produce traces of the highest quality.

\section{Drop coating deposition Raman spectroscopy}

The samples of mNKR-P1A/C $(4 \mu \mathrm{L}$ ) were dialyzed (on Millipore filters $0.025 \mu \mathrm{m} / \mathrm{white}$ VSWP/13 mm) against deionized distilled water for 35 minutes. A $2 \mu \mathrm{L}$ volume of protein 
solution, with an approximate concentration of $1 \mathrm{mg} / \mathrm{mL}$, was deposited on a standard DCDR substrate SpectRIM ${ }^{\mathrm{TM}}$ (Tienta Sciences) consisting of a polished stainless steel plate coated with a thin layer of Teflon [6]. After air-drying at room temperature, approximately 20 minutes, Raman spectra were collected from "coffee rings" of former droplets [7] using a Raman microspectrometer HR800 (Horiba Jobin Yvon) with a $514.5 \mathrm{~nm}$ Ar-ion excitation laser (Melles Griot). A 50× microscope objective (N.A. 0.75, Olympus) was used to focus the $5 \mathrm{~mW}$ excitation laser to a diameter, approximately $1.5 \mu \mathrm{m}$, on the sample, and the spectra were integrated for $20 \mathrm{~min}$ using a 600 grooves $/ \mathrm{mm}$ grating and liquid nitrogen cooled CCD detector $(1024 \times 256$ pixels, Symphony). The spectrometer was calibrated using a band of Sivibrations at $520.7 \mathrm{~cm}^{-1}$. The spectral resolution was approximately $5 \mathrm{~cm}^{-1}$.

The samples of rNKR-P1A/B proteins were treated in the same way as the mouse proteins. Nevertheless, the spectra of rNKR-P1A/B protein were integrated for 4 min using a $632.8 \mathrm{~nm}$ $\mathrm{He}-\mathrm{Ne}$ laser excitation in the same setup as mentioned previously.

\section{Infrared spectroscopy}

Infrared spectra of mNKR-P1A/C proteins were recorded with a Bruker Vector 33 FTIR spectrometer using a standard MIR source, a KBr beamsplitter and a DTGS detector. 5000 scans were collected with a Blackman-Harris 3-term apodization function at a spectral resolution of $2 \mathrm{~cm}^{-1}$. Aqueous protein solutions were measured at room temperature in a $\mathrm{CaF}_{2}$ cell with a $10 \mu \mathrm{m}$ path length. Measurements in thermal dynamics were performed using a thermal cell holder BioJACK ${ }^{\mathrm{TM}}$ (BioTools). Temperature was adjusted from 5 to $90{ }^{\circ} \mathrm{C}$ with an increment of $5{ }^{\circ} \mathrm{C}$ using an en external water bath (Neslab) and equilibrated for 4 minutes before measurements took place. 1000 scans were performed. Attenuated total reflection (ATR) FTIR measurements, 5000 scans, were realized by using an ATR-MIRacl ${ }^{\text {TMAG }}$ single diamond horizontal ATR (Pike Technologies).

The rNKR-P1A/B proteins were measured using a Bruker IFS 66/S FTIR spectrometer equipped with an MCT detector. 4000 scans were collected with a Happ-Genzel apodization function at a spectral resolution of $4 \mathrm{~cm}^{-1}$. The rest of the FTIR setup remained the same as the measurements for mNKR-P1 proteins. Spectral contribution of the buffer was corrected following the standard algorithm [8]. Spectrum of water vapors was subtracted and finally, all spectra were normalized. 


\section{Differential scanning calorimetry}

The protein's stock solutions were diluted to the desired concentration - i.e. mNKR-P1A to $0.20 \mathrm{mg} / \mathrm{mL}$ and $\mathrm{mNKR}-\mathrm{P} 1 \mathrm{C}$ to $0.52 \mathrm{mg} \mathrm{ml}^{-1}$. Calorimetric measurements were performed using the Model 6100 Nano II Differential Scanning Calorimeter - N-DSC II (Microcalorimetry Sciences Corporation). The samples were scanned from 5 to $90{ }^{\circ} \mathrm{C}$ at a heating rate of $1{ }^{\circ} \mathrm{C} / \mathrm{min}$ under a constant excess pressure of 3 atmospheres. The appropriate DSCRun and CpCalc 2.2 software was used for data acquisition and analysis. After baseline subtraction of the buffer-buffer signal, the molar excess heat capacity function was obtained by dividing the protein concentration and cell volume $(0.299 \mathrm{ml})$.

\section{Sequence and phylogeny analysis}

Sequences specified in Table 1 were aligned in ClustalX [21] and used for phylogeny analysis. For sequence analysis purposes, we used only their C-type lectin-like domains resultant trees however revealed too many polytomies. The number of polytomies was decreased by using nucleotide sequences for tree construction. Excluding Bayesian analyses, all protein and DNA sequences analyses were performed using Phylip 3.69 software [22] with the following algorithms: Neighbor-Joining [23], maximum parsimony [24], maximum likelihood [25] with assuming molecular clock and Fitch-Margoliash method assuming molecular clock (Kitsch method) [26]. Sequences were bootstrapped 1000x with the exception of the computationally most expensive method maximum likelihood, where sequences were bootstrapped $100 \times$. To confirm that this value of bootstrapping was high enough, we constructed the trees with the same settings but bootstrapped $1100 \times$ or $110 \times$. To calculate the distance matrix, and for the maximum likelihood method, we used the JonesTaylor-Thornton matrix for protein sequences and the F84 matrix for DNA sequences. Where possible the sequences were jumbled $5 \times$. In the Neighbor-Joining method the order of sequences was randomized. Probabilities of branch occurrence were calculated according to one of the most commonly used tests on the reliability of an inferred tree, Felsenstein's bootstrap test [27], which was evaluated using Efron's [28] bootstrap resampling technique. Resultant consensus cladograms were done using the $50 \%$ majority consensus rule. Bayesian analysis was performed using MrBayes 3.1.2 [29] with the same initial sequences used previously. Invariable gamma distribution and a GTR model was used to describe the 
parameters for the likelihood model, 150000 for protein cycles and 100000 for DNA Markov chain Monte Carlo cycles, with the state being swapped every 100x.

\section{Homology modeling}

Primary structures of mouse NKR-P1A, mNKR-P1C, rNKR-P1A, and rNKR-P1B extracellular domains were extracted from the database (Table 1). Templates were identified using BLAST [30] with matrix BLOSUM62. The identified homologs were almost the same for all seven models that were built. The template with highest identity to the target sequence was used. If some structures had the same identity, the one with the better resolution was used. Templates and identities used were: 1YPQ (C-type lectin-like domain of human oxidized low density lipoprotein receptor 1 (LOX-1) [31]) for mNKR-P1A/C (identity $31 \% / 32 \%)$, 1XPH (CD209 antigen-like protein 1 [32]) for rNKR-P1B (identity $33 \%$ ), 3HUP (early activation antigen CD69 [33]) for mNKR-P1F (identity 33\%), 1E87 (early activation antigen CD69 [34]) for mNKR-P1G (identity 35\%) and 2BPD (beta-glucan receptor Dectin-1 [35]) for hNKR-P1 (identity $32 \%$ ). Only in the case of rNKR-P1A was an alternative technique tried. The neighboring sequence from the Neighbor-Joining phylogenetic tree $(1000 \times$ bootstrapped) was used, i.e., structure 3CAD (lectin-related NK cell receptor LY49G1 [36]). Alignment of template and modeled sequences used ClustalX. Alignments were checked to ensure that general features in sequence-conserved regions of CTLDs, were maintained as found in sequence multiple alignments of CTLDs. The resulting aligned sequences used for modeling are shown in Fig. 8. Ten models were calculated for every protein and template using Modeller 9v4 [37]. The best model from every group was chosen by the distribution of amino acids in the Ramachandran plot and stereochemical $g$ factor (both calculated by Procheck [38]), Modeller distribution function and by visual inspection using SwissPDBViewer [39]. Secondary structure was determined by Procheck according to Kabsch and Sander [40].

\section{Molecular dynamics}

All selected models were minimized in SCP water solution with Gromacs 3.3.3 package [41], using virtual site hydrogens. The modified version of force field Gromos87 (usually called Gromacs) [42, 43] was used. Temperature was held at $300 \mathrm{~K}$ by separately connecting the protein and solution to the external temperature bath $(t=0.1 \mathrm{ps})$ while the pressure was held 
at 1 bar by connecting to the pressure bath $(\mathrm{t}=0.1 \mathrm{ps})$. Algorithms SETTLE (for water) and LINCS (for protein) were used to restrict covalent bond length and long-range electrostatic interactions were calculated using the Particle-Mesh Ewald method. Optimization with steepest descent energy minimization was followed by solvent optimization using a time step of $1 \mathrm{fs}$ for $10 \mathrm{ps}$. Counter ions were added to neutralize the simulation box and were consequently minimized for $10 \mathrm{ps}$ using a time step of $1 \mathrm{fs}$. Finally, the protein was minimized for $20 \mathrm{ps}$ using a time step of $2 \mathrm{fs}$. For production, the simulation runs were started using a time step of $5 \mathrm{fs}$. Root mean square deviation and radius of gyration analysis was performed every $10 \mathrm{~ns}$ to check if the system reached equilibrium. The total production run time was $110 \mathrm{~ns}$ for mNKR-P1A, $10 \mathrm{~ns}$ for rNKR-P1A, $20 \mathrm{~ns}$ for rNKR-P1B and $100 \mathrm{~ns}$ for mNKR-P1C. The human and mouse models NKR-P1F/G were equilibrated for $10 \mathrm{~ns}$.

After the dynamics run, all structures were minimized using the steepest descent algorithm. The representation of secondary structure types according to Kabsch and Sander [40] was calculated by Procheck software, and the root mean square fluctuation for each residue was calculated in Gromacs.

\section{Results and discussion}

\section{Structural analysis of NKR-P1 proteins}

Four NKR-P1 extracellular domains, rNKR-P1A and B and mNKR-P1A and C, were overexpressed in E. coli, refolded from inclusion bodies, and purified for spectroscopic analysis as described in Methods. Receptor domains were structurally analyzed by Raman, FTIR, and ATR-FTIR spectroscopy, including a novel drop-coating deposition Raman method that yields native-state spectra from very small solid samples [7]. Spectral assignments are given in Table 2, and secondary structure contents estimated using the pattern recognition least-squares method (LSA) are given in Table 3.

Fig. 1 compares the FTIR spectra of mNKR-P1A and C domains. The similarity of the spectra is immediately obvious, indicating that mouse $\mathrm{A}$ and $\mathrm{C}$ proteins share the same fold with very similar secondary structure content. The slight differences in the spectra can be explained by 
their different amino acid compositions. For example, the second derivative band at $1517 \mathrm{~cm}^{-1}$ is connected with Tyr ring vibrations [54], and is more intense in mNKR-P1A that has five Tyr residues that in mNKR-P1C with only one Tyr. ATR-FTIR spectra of proteins were also measured for better resolution of subtle differences, and no further differences were detected (data not shown). The FTIR results are in excellent agreement with Raman spectroscopy data (Fig. 2 and Table 3). Solution Raman spectra (not shown) are also highly similar to dropcoated deposition spectra, which provide better signal-to-noise ratio.

The secondary structure estimates using the LSA method, which analyzes the amide I band in the case of Raman spectroscopy [49], and amide I and II bands in FTIR spectra [50], are not perfect for mNKR-P1A and C domains, suggesting a protein fold whose spectral pattern is not included in the LSA reference set [51]. Thus, the absolute percentages in the secondary structure content probably contain larger errors than estimated in Table 3. The fits for Raman spectral data are better. Nevertheless, both FTIR and Raman spectroscopy predictions differ by no more than $4 \%$ in each method for mouse $\mathrm{A}$ and $\mathrm{C}$ variants, and for each variant some predictions are in agreement within the margin of error. These results thus suggests only a small difference in the content of $\alpha$-helices and $\beta$ strands of about $10 \%$ for the two mouse domains.

Negative bands are observed in the Raman difference spectrum between mouse variants A and $\mathrm{C}$ in the region reporting on S-S-bridge conformations (Fig. 2). The presence of these intense and narrow vibration bands reflects a more well-defined conformation of $\mathrm{S}-\mathrm{S}$ bridges in $\mathrm{mNKR}-\mathrm{P} 1 \mathrm{C}$ and thus lower flexibility. Thus, the $\mathrm{C}$ variant is probably more rigid than the A variant, in agreement with the higher stability detected in calorimetric data as discussed below.

More distinctive differences can be seen between the FTIR spectra of rNKR-P1A and B domains (Fig. 3). The band positions of the rat A variant differ only slightly more than the differences between the two mouse variants, and therefore the rat A variant can be structurally clustered with both mouse variants; rNKR-P1B is the most distinctive protein within the measured group. Raman difference spectroscopy (Fig. 4) adds detail to these distinctions, with significant differences between A and B variants in the amide I region, ca. $1671 \mathrm{~cm}^{-1}$ and amide III, ca. $1237 \mathrm{~cm}^{-1}$. In the amide III region, the positive band, ca. $1230 \mathrm{~cm}^{-1}$, corresponds to an excess of $\beta$-structures in rNKR-P1A relative to the $\mathrm{B}$ variant. The negative band at $1280 \mathrm{~cm}^{-1}$ corresponds to lower $\alpha$-helix content in the A variant when compared with the B
Comment [EH2]: Comment for typesetter: Ref 44-47 are cited in Table 2 Ref 48 is cited in figure caption of Fig.2 Ref 49-51 are cited in Table 3 Ref $52-53$ is cited in figure caption of Fig.1 
variant. The aromatic amino acid composition of rNKR-P1A/B domains are the same; thus the Raman difference spectrum in Fig. 4 reflects mostly secondary structure differences between the proteins. Comparing all Raman spectra, rNKR-P1B protein is again the most distinctive, with mouse $\mathrm{A}$ and $\mathrm{C}$ variants very similar, and rat variant $\mathrm{A}$ being somewhere in between.

\section{Thermal dynamics}

Differential scanning calorimetry showed an irreversible denaturation transition for mNKR$\mathrm{P} 1 \mathrm{~A}$ and $\mathrm{C}$ domains corresponding to a single, noncooperative thermal transition, with melting temperatures of $69^{\circ} \mathrm{C}$ for mNKR-P1A and $72{ }^{\circ} \mathrm{C}$ for the $\mathrm{C}$ variant (data not shown). Thermodynamic parameters for the transitions, determined as described in Methods, were the same for both proteins, $\Delta H=48 \mathrm{kcal} \mathrm{mol}{ }^{-1}, \Delta S=0.14 \mathrm{kcal} \cdot \mathrm{K}^{-1} \cdot \mathrm{mol}^{-1}$. Therefore the $\mathrm{mNKR}$ $\mathrm{P} 1 \mathrm{C}$ domain is slightly more thermostable than the A variant.

Two-dimensional correlation spectroscopy (2DCoS) was applied to FTIR and Raman spectra to add structural detail to the thermal unfolding transitions of mNKR-P1A/C proteins. The aim of this technique is to identify in-phase and out-of-phase correlations between spectral intensity variations occurring at different wavenumbers that are induced by external perturbation of the studied system; a generalized formalism for 2DCoS can be found in ref. 57-59. The main advantage of $2 \mathrm{DCOS}$ is that it allows enhancement of spectral resolution by spreading overlapping bands over a second dimension. In addition, sign analysis of the correlation peaks in the 2D maps may improve band assignment and permit establishment of a sequence of events during the perturbation process [57-59].

Synchronous 2D correlation FTIR spectra (Fig. 5 left) suggest slightly lower stability in the A variant relative to $\mathrm{C}$, in agreement with calorimetric data, and suggest this transition is correlated with exposure of hydrophobic regions in $\beta$-strands. The Raman synchronous spectrum is significantly less complicated (Fig. 6 left) and reports on the same denaturation process, consistent with the FTIR results. The asynchronous 2DCoS spectra (Fis. 5 and 6 right) reveal sequential, but not coincidental, spectral changes. The asynchronous spectrum has no autopeaks and consists exclusively of crosspeaks that are antisymmetric in regard to the diagonal line. Asynchronous cross peaks develop only if the intensities of two spectral features change and are out of phase with each other. If the asynchronous peak sign becomes

Comment [EH3]: Comment for typesetter: Ref 55-56 are cited in figure caption of Fig,2 
positive then the intensity change at the given wavenumber on the $x$-scale occurs predominantly before it is connected with the $2 \mathrm{DCoS} y$-scale and vice versa. This sign rule is reversed if the synchronous correlation intensity at the same coordinate becomes negative.

Application of these so called Noda rules [57-59] to mNKR-P1C second derivative FTIR spectra indicate the following sequential order of structural changes. Changes in $\beta$-turns occur first, followed by an increase in $\beta$-sheet content, then changes in $\alpha$-helices followed by changes in loops. These structural changes precede emergence of $\beta$-aggregated structures, which is followed by changes in $\beta$-turns. The sequential order in the mNKR-P1A variant is the same, although the emergence of $\beta$-aggregates was not observable. The sequential order of secondary structure changes from FTIR is in agreement with that from Raman data. Asynchronous analysis of Raman data shows that changes in Tyr/Phe vibration at $1600 \mathrm{~cm}^{-1}$ precede changes in $\beta$-turns, and the increase of $\beta$-sheet content is followed by changes in Trp/Phe vibrations at $1590 \mathrm{~cm}^{-1}$.

Heterospectral 2DcoS was used because it can reveal correlations between different spectral regions or even between two different spectroscopic techniques and may help to detect vibrations of a similar nature or connections with the same process [59]. Only synchronous heterospectral 2DCoS Raman spectroscopy was used to permit direct correlation of secondary structure elements with specific residue types, and because Raman spectra contain more residue-specific spectral information than FTIR spectra. The synchronous spectra display only cross peaks (Fig. 7) because autopeaks are generated only by the correlation of the same bands as in Figs. 5 and 6. Correlations were investigated in the changes of the secondary structure, represented by the Raman amide I region $\left(1580-1700 \mathrm{~cm}^{-1}\right)$, and the regions where aromatic side chains have intense Raman bands. The strong correlations reported in Fig. 7 suggest that one or more Trp residues experience major changes in their surroundings during the early stages of thermal denaturation.

The structural changes occurring in NKR-P1 proteins during the increase of temperature can be interpreted tentatively as follows. Some large flexible part with high content of $\beta$-turns is rearranged first. Trp residues appear to be involved in significant dynamical behavior during these early stages of denaturation. Next, the $\beta$-sheet content increases before or during continuous decrease of $\alpha$-helix content. These changes lead to the exposure of a hydrophobic 
region, perhaps containing Tyr and/or Phe residues, leading to $\beta$-aggregates followed by changes in $\beta$-turns.

\section{Modeling}

\section{Homology modeling and molecular dynamics}

Candidate template sequences were identified using BLAST [30] and pair-aligned with modeling target sequences using ClustalX as described in Methods. The template structure with highest sequence identity to each target was used for modeling; identities ranged from 31 to $35 \%$, and the resulting aligned sequences used for modeling are shown in Fig. 8. Template structures used were: 1YPQ (C-type lectin-like domain of human oxidized low density lipoprotein receptor 1 (LOX-1) [31]) for mNKR-P1A/C, 1XPH (CD209 antigen-like protein 1 [32]) for rNKR-P1A/B, 3HUP (early activation antigen CD69 [33]) for mNKR-P1F, 1E87 (early activation antigen CD69 [34]) for mNKR-P1G, and 2BPD (beta-glucan receptor Dectin-1 [35]) for hNKR-P1. These template structures are similar to each other as judged by $\mathrm{C} \alpha$ root-mean-square deviations ranging from 0.94 to 1.50 among them, and all have functions close to those of the NKR-P1 proteins [61]. C-type lectin-like NK receptors are dimeric in their nature, but as the mode of dimerization is not conserved within this receptor family, we did not attempt to model NKR-P1s as dimers. Moreover, in native receptors covalent linkage by one or more disulfide bridges in the so-called "stalk region" close to the cell membrane is involved in dimerization. This region is usually omitted from soluble recombinant receptor domain constructs and thus is also missing in available crystal structures. Finally, all recombinant NKR-P1s prepared in this study behaved like a monomeric species during their purification (data not shown), pointing out for rather weak dimer formation within the NKR-P1 family, however, we cannot exclude that cooperativity between monomers will occur upon ligand binding. For consistency, the numbering of sequences begins at residue 89 in all sequences, and specific residue numbers discussed in the text are those of the mNKR-P1A sequence. Ten models were calculated for every sequencetemplate pair using Modeller 9v4 [37]. For further analysis the best model from every group was chosen as described in Methods, and refined by at least $10 \mathrm{~ns}$ of molecular dynamic simulations at room temperature in explicit solvent. 
All models share the same basic $\alpha / \beta$ fold represented in Fig. 9 by rNKR-P1B. Helices surround a beta core composed of long antiparallel $\beta$-strands 2 and 8 that form a central 'pillar' flanked at one end by short strands 1 and 3 and at the other end by a small antiparallel sheet formed by strands 4-7. Although $\beta$-strand 3 is very short, its residues are highly conserved and they adopt very similar positions in all models (Table 4). The lengths of secondary structure elements (Table 5) reveal that a conserved number of residues forms strands 2 and 8 of the central pillar except in mNKR-P1F that is 1-2 residues shorter. These strands define the height of the receptor on the outside surface of the cell membrane. The models contain the three disulfide bonds identified in experimental data [62], except for mNKR-P1C where Cys122 is replaced by Ser.

Although the core of the protein is nearly the same for all seven models $(\mathrm{C} \alpha$ rmsd $<2 \AA$ for the beta core defined above), the number and orientation of helices as well as the topological organization of secondary elements vary somewhat among the models, defining four groups (Fig. 10). Mouse NKR-P1A/C models are more similar to each other than rat models are to each other. In addition to the topology differences, the prominent loops anchored by small antiparallel sheets differ in their arrangement among models, making rmsd comparisons meaningless for these segments. In all cases one small sheet (residues Ala127, Tyr128 and Leu129 in mNKR-P1A) anchors one loop of $\sim 5$ to 7 residues (residues Met130 to Gln135 in mNKR-P1A, green loop in Fig. 10, first half of region III in Fig. 12) and another small sheet (residues Trp165, Lys166 and Trp167 in mNKR-P1A) anchors one long loop of $\sim 19$ residues (e.g., residues Arg168 to Asp187 in mNKR-P1A, blue loop between sheets 5 and 6 in Fig. 10, region $\mathrm{V}$ until beginning of region IVb in Fig. 12). In rNKR-P1B and hNKR-P1 the long loop contains an additional short helix that packs on one side of the core together with helix B. In rNKR-P1B the connectivity of the loops to the small sheet also differs.

These differences in the spatial arrangement of the loops among the models are reflected also in the behavior of each model in molecular dynamics simulations. In all simulations the protein core is stable, with Ca rmsds reaching plateau values of $\sim 1.3$ to $2.5 \AA$ (data not shown). The root mean square fluctuations for Ca calculated from the last nanosecond of the equilibrated part of each trajectory clearly identify the long loop region as very flexible (Fig. 11). Both ends of the loop, immediately after the $\mathrm{N}$ - and C-terminal anchoring residues, are extremely flexible. The root mean square fluctuations of the other residues in the loop are slightly higher than the average for the whole protein, although the structure within the loop is stable in the time period that could be simulated. The N-terminal anchoring residues are the 
highly conserved WKW sequence motif (residues Trp165, Lys166 and Trp167 in mNKRP1A). The loop occasionally folds back onto the protein surface, where it forms a hydrophobic interaction with the two tryptophan residues. Together these results suggest that the loop region is stably anchored to the core, but can adopt alternative positions relative to the core.

\section{Sequence analysis}

The 33 available NKR-P1 CTLD domain sequences (Table 1) were aligned in ClustalX [21]. Seven conserved regions are identifiable (Fig. 12). Among these regions, conservation among orthologs is highest in the beta core and lowest in the two loops, the smaller loop corresponding to region III and the large loop corresponding to region V. In region III the chemical properties of loop residues are preserved despite the sequence variations. In contrast, substitutions in extended region V (L160 to T183) cause significant changes in the chemical character of some loop residues among natural NKR-P1 variants, leading to two groups typified by NKR-P1 subfamilies A-D and F/G. The NKR-P1A/D group presents L160, N164, T171, K178 and T183, whereas the NKR-P1F/G group substitutes a polar residue (Glu or Gln) for Leu160, a beta-branched residue (Thr, Val, or Ile) for Asn164, a more hydrophobic residue (Ile or Val) for Thr171, a Ser or Lys residue for Arg178, and a more polar residue (Asn, Asp, or Glu) for Thr183. The results of in vivo binding experiments with C-type lectin receptor $(\mathrm{Clr})$ isoforms [11] suggest that these sequence differences may be related to ligand specificity: rNKRP1A and rNKRP1B bind to Clr11 only; rNKRP1F and rNKRP1G bind to Clr2, Clr6, and Clr7 but not to Clr11, and rNKRP1F also binds to Clr3 and Clr4. Thus, the long adaptable loop of the C-type lectin-like domain may encode its ligand specificity.

\section{Phylogenetic analysis}

Phylogenetic analysis was originally performed with only the protein sequences of the C-type lectin-like domains, starting at position 89 for mouse NKR-P1A. Although five methods gave similar results, cladograms contained a large number of polytomies. DNA nucleotide sequences were then applied to bring in additional information for tree construction. Cladograms based on DNA sequences were constructed with several different approaches as described in Methods, leading to nearly identical results. In every case, the major branches of the cladogram were the same, as confirmed by bootstrapping. Bootstrapping failed only when 
the arrangement of species within the clade was different. This robustness of the final result supports the principal correctness of the tree. The resultant cladogram obtained by the maximum-likelihood method is shown in Fig. 13. Where some methods suggest polytomy or further branching, both possibilities are drawn.

The cladogram displays three major branches. The first is composed of human and chicken NKR-P1s. The second main branch is composed of rodent NKR-P1s from the telomeric part of the NK gene complex. In this branch the sequences are first branched according to the receptor subfamily and then according to the species. The third major group consists of rodent receptors from the centromeric part of the NK gene complex. Here, the sequences are ordered first according to species and then according to receptor subfamily. The most undefined part of the cladogram includes the rat NKR-P1As, as some methods even create pentatomy.

\section{Comparison of modeling and spectroscopic results}

The extent of predicted $\alpha$-helical structure in rNKR-P1B agrees closely with experiments, especially with the data from FTIR. In the case of mNKR-P1A/C, more $\alpha$-helical structure is detected in the spectra than is present in the models. One likely explanation that would be in quantitative agreement with the data is that short $\alpha$-helix $\mathrm{C}$, which is present in human and rat NKR-P1B models, is also present in both mouse structures. In the case of $\beta$-strands, the algorithm used to determine hydrogen bonds in models uses an average cutoff value, whereas in nature this cutoff is not so sharp, and it also depends on the $\beta$-strand environment and other factors. The agreement between the spectroscopic data and the models is particularly strong for beta turns, especially when measured by FTIR, whereas Raman spectra give slightly higher turns content. The phylogeny depicted in Fig. 13 is also consistent with the vibrational spectra, which group mouse $\mathrm{A} / \mathrm{C}$ variants together as most distinct from rNKR-P1B, and with rat variant $\mathrm{A}$ being somewhere in between.

Disulfide bond conformations for Cys122-210 and Cys94-105 are unambiguously in a GGG conformation in all computational models. Therefore these two bridges can be assigned to the two clear GGG conformations determined from the band at $509 \mathrm{~cm}^{-1}$ (Fig. 2) representing the disulfide bridges region of stretching vibrations. The third disulfide bridge between Cys189202 in the models adopts conformations in between the more rare GGT and TGT conformations, and could be assigned to the TGT conformation observed experimentally (Fig. 2). 
The inferred conformational adaptability of the long loop region finds support in the spectroscopic data as well. Opening of the loop as suggested by its behavior in molecular dynamics simulations would expose the two anchoring tryptophan residues to solvent, in agreement with the early shifts observed for tryptophan residues in the experimental thermal dynamics data.

\section{Conclusions}

MD-refined homology models of rat NKR-P1A/B, mouse NKR-P1A/C/F/G and human NKR$\mathrm{P} 1$ receptor C-type lectin-like extracellular domains were generated in order to understand evolution of the structural features determining their functions. The rat NKR-P1A/B and mouse NKR-P1A/C domains were structurally analyzed by Raman and FTIR spectroscopy. Combined protein and DNA sequence analysis divided NKR-P1s into three major phylogenetic groups.

The derived models agree well with the Raman and infrared spectra not only in terms of overall secondary structure content, but additionally the models capture key structural and dynamic features consistent with thermal dynamics and MD simulations. Two sequence regions that are conserved in all analyzed NKR-P1s, and thus under strong evolutionary pressure, define the major phylogenetic branches, including the distinction between the NKRP1A/D and the NKR-P1F/G subfamilies. One of these regions is the long loop present in nearly every CTLD; it is alternatively arranged in the different models, and is predicted to contain only a minor portion of secondary structure that is variably present. The experimental data from vibrational thermal analysis would be consistent with the facile dynamics of this region observed in MD simulations, in which an underlying hydrophobic surface becomes exposed. Sequence and phylogenetic analysis suggests that this loop region evolved in concert with target specificity, adapting the chemical properties of the residues to specific target ligands while embedding them in a structurally stable framework. The results thus suggest that the long loop plays a key role in ligand specificity, and that a conformational equilibrium is involved in ligand binding.

Homology modeling is based on the presumption that proteins with similar primary structures (> $30 \%$ identity) have the same tertiary structure. Even though exceptions are known [e.g. 
$63,64]$, the use of templates with functions close to those of the modeled targets in the present case suggested that this basic assumption should be correct, and that the core folds are likely to be similar. Local deviations can occur, and these may be detected by combining vibrational spectroscopy with computational modeling [65], as shown by the results presented here.

The resulting molecular models of NKR-P1 are available upon request.

\section{Acknowledgments}

The Grant Agency of the Academy of Sciences of the Czech Republic and the Ministry of Education of the Czech Republic are gratefully acknowledged for support (LC 06010, No. KJB101120805, Nos. MSM6007665808, MSM 0021620835, MSM 0021620808, 1M0505, AVOZ60870520, AV0Z50200510 respectively). Additionally, Z.S. was supported by the University of South Bohemia, grant GAJU 170/2010/P. Access to the METACentrum computing facilities provided under the research intent MSM6383917201 is highly appreciated. 


\section{References}

1. Lanier LL (1998) NK Cell receptors. Annu Rev Immunol 16:359-393

2. Vivier E, Tomasello E, Baratin M, Walzer T, Ugolini S (2008) Function of natural killer cells. Nat Immunol 9:503-510

3. Ljunggren HG, Karre K (1990) In search of 'missing self': MHC molecules and NK cell recognition. Immunol Today 11:237-244

4. Plíhal O., Byrtusová P., Pavlíček J., Mihók L., Ettrich R., Man P., Pompach P., Havlíček V., Hušáková L., Bezouška K. (2004) The isoforms of rat natural killer cell receptor NKR-P1 display a distinct binding of complex saccharide ligands. Collect Czech Chem Commun 69:631-644

5. Bradford MM (1976) A rapid and sensitive method for the quantitation of microgram quantities of protein utilizing the principle of protein-dye binding. Anal Biochem 72:248254

6. Zhang D, Xie Y, Mrozek MF, Ortiz C, Davisson VJ, Ben-Amotz D (2003) Raman detection of proteomic analytes. Anal Chem 75:5703-5709

7. Kopecký V Jr, Baumruk V (2006) Structure of the ring in drop coating deposited proteins and its implication for Raman spectroscopy of biomolecules. Vibr Spectrosc 42:184-187

8. Dousseau F, Therrien M, Pézolet M (1989) On the spectral subtraction of water from FTIR spectra of aqueous solutions of proteins. Appl Spectrosc 43:538-542

9. Voigt S, Mesci A, Ettinger J, Fine JH, Chen P, Chou W, Carlyle JR (2007) Cytomegalovirus Evasion of Innate Immunity by Subversion of the NKR-P1B:Clr-b Missing-Self Axis. Immunity 26:617-627

10. Giorda R, Rudert WA, Vavassori C, Chambers WH, Hiserodt JC, Trucco M (1990) NKR-P1, a signal transduction molecule on natural killer cells. Science 249(4974):12981300

11. Kveberg L, Dai KZ, Westgaard IH, Daws MR, Fossum S, Naper C, Vaage JT (2009) Two major groups of rat NKR-P1 receptors can be distinguished based on chromosomal localization, phylogenetic analysis and Clr ligand binding. Eur J Immunol 39: 541-551

12. Dissen E, Ryan JC, Seaman WE, Fossum S (1996) An autosomal dominant locus, Nka, mapping to the Ly-49 region of a rat natural killer (NK) gene complex, controls NK cell lysis of allogeneic lymphocytes. J Exp Med 183:2197-2207 
13. Appasamy PM, Kenniston TW, Brissette-Storkus CS, Chambers WH (1996) NKRP1dim/TCR alpha beta $+\mathrm{T}$ cells and natural killer cells share expression of NKR-P1A and NKR-P1D. Nat Immunol 15(5):259-268

14. Giorda R, Trucco M (1991) Mouse NKR-P1. A family of genes selectively coexpressed in adherent lymphokine-activated killer cells. J Immunol 147(5):1701-1708

15. Carlyle JR, Mesci A, Ljutic B, Belanger S, Tai LH, Rousselle E, Troke AD, Proteau MF, Makrigiannis AP (2006) Molecular and genetic basis for strain-dependent NK1.1 alloreactivity of mouse NK cells. J Immunol 176(12):7511-7524

16. Kung SK, Su RC, Shannon J, Miller RG (1999) The NKR-P1B gene product is an inhibitory receptor on SJL/J NK cells. J Immunol 162(10):5876-5887

17. Carninci P, Hayashizaki Y (1999) High-efficiency full-length cDNA cloning. Methods Enzymol 303:19-44

18. Plougastel B, Matsumoto K, Dubbelde C, Yokoyama WM (2001) Analysis of a 1-Mb BAC contig overlapping the mouse Nkrp1 cluster of genes: cloning of three new Nkrp1 members, Nkrp1d, Nkrp1e, and Nkrp1f. Immunogenetics 53(7):592-598

19. Lanier LL, Chang C, Phillips JH (1994) Human NKR-P1A. A disulfide-linked homodimer of the C-type lectin superfamily expressed by a subset of NK and T lymphocytes. J Immunol 153(6):2417-2428

20. Kaufman J, Milne S, Gobel TW, Walker BA, Jacob JP, Auffray C, Zoorob R, Beck S (1999) The chicken B locus is a minimal essential major histocompatibility complex. Nature 401(6756):923-925

21. Larkin MA, Blackshields G, Brown NP, Chenna R, McGettigan PA, McWilliam H, Valentin F, Wallace IM, Wilm A, Lopez R, Thompson JD, Gibson TJ, Higgins DG (2007) Clustal W and Clustal X version 2.0. Bioinformatics 23:2947-2948

22. Felsenstein J (1989) PHYLIP - phylogeny inference package (version 3.2). Cladistics 5:164-166

23. Saitou N, Nei M (1987) The neighbor-joining method: A new method for reconstruction phylogenetics trees. Mol Biol Evol 4:406-425

24. Eck RV, Dayhoff MO (1966) Atlas of protein sequence and structure. National Biomedical Research Foundation, Silver Spring, MD

25. Felsenstein J (1973) Maximum-likelihood and minimum-steps methods for estimating evolutionary trees from data on discrete characters. Syst Zool 22:240-249

26. Fitch WM, Margoliash E (1967) Construction of phylogenetics trees. Science 155:279_ 284 
27. Felsenstein J. (1985) Confidence-limits on phylogenies - an approach using bootstrap. Evolution 39(4):783-791

28. Efron B (1982) Maximum-likelihood and decision-theory. Ann Stat 10(2):340-356

29. Ronquist F, Huelsenbeck JP (2003) MRBAYES 3: Bayesian phylogenetic inference under mixed models. Bioinformatics 19:1572-1574

30. Altschul SF, Gish W, Miller W, Myers EW, Lipman DJ (1990) Basic local alignment search tool. J Mol Biol 215:403-410

31. Park H, Adsit FG, Boyington JC (2005) The $1.4 \AA$ crystal structure of the human oxidized low density lipoprotein receptor lox-1. J Biol Chem 280:13593-13599

32. Snyder GA, Colonna M, Sun PD (2005) The structure of DC-SIGNR with a portion of its repeat domain lends insights to modeling of the receptor tetramer. J Biol Chem 347:979989

33. Kolenko P, Skalova T, Vanek O, Stepankova A, Duskova J, Hasek J, Bezouska K, Dohnalek J (2009) The high-resolution structure of the extracellular domain of human CD69 using a novel polymer. Acta Crystallogr F 65: 1258-1260

34. Llera AS, Viedma F, Sanchez-Madrid F, Tormo J (2001) Crystal structure of the C-type lectin-like domain from the human hematopoietic cell receptor Cd69. J Biol Chem 276(10):7312-7319

35. Brown J, O’Callaghan CA, Marshall ASJ, Gilbert RJC, Siebold C, Gordon S, Brown GD, Jones EY (2007) Structure of the fungal beta-glucan-binding immune receptor dectin-1: Implications for function. Protein Sci 16: 1042-1052

36. Deng L, Cho S, Malchiodi EL, Kerzic MC, Dam J., Mariuzza RA (2008) Molecular architecture of the major histocompatibility complex class I-binding site of Ly49 natural killer cell receptors. J Biol Chem 283:16840-16849

37. Eswar N, Marti-Renom MA, Webb B, Madhusudhan MS, Eramian D, Shen M, Pieper U, Sali A (2006) Comparative protein structure modeling with MODELLER. Current Protocols in Bioinformatics, Wiley, Supplement 15, 5.6.1-5.6.30

38. Laskowski RA, MacArthur MW, Moss DS, Thornton JM (1993) PROCHECK: a program to check the stereochemical quality of protein structures. J Appl Cryst 26:283291

39. Guex N, Peitsch MC (1997) SWISS-MODEL and the Swiss-PdbViewer: An environment for comparative protein modeling. Electrophoresis 18:2714-2723

40. Kabsch W, Sander C (1983) Dictionary of protein secondary structure: Pattern recognition of hydrogen bonded and geometrical features. Biopolymers 22:2577-2637 
41. van der Spoel D, Lindahl E, Hess B, Groenhof G, Mark AE, Berendsen HJ (2005) GROMACS: fast, flexible, and free. J Comput Chem 26 (16):1701-1718

42. van Buuren AR, Marrink SJ, Berendsen HJC (1993) A molecular dynamics study of the decane/water interface. J Phys Chem 97:9206-9212

43. Mark AE, van Helden SP, Smith PE, Janssen LHM, van Gusteren WF (1994) Convergence properties of free energy calculations: $\alpha$-cyclodextrin complexes as a case study. J Am Chem Soc 116:6293-6302

44. Tensmeyer LG, Kaufman EW (1996) Protein structure as revealed by nonresonance Raman spectroscopy. In: Havel HA (ed) Spectroscopic methods for determining protein structure in solutions. VCH Publishers Inc, New York, pp 69-93

45. Overman SA, Thomas GJ Jr (1999) Raman markers of nonaromatic side chains in an ahelix assembly: Ala, Asp, Glu, Gly, Ile, Leu, Lys, Ser, and Val residues of phage $f d$ subunits. Biochemistry 38:4018-4027

46. Tuma R (2005) Raman spectroscopy of proteins: from peptides to large assemblies. J Raman Spectrosc 36:307-319

47. Miura T, Thomas GJ Jr (1995) Raman spectroscopy of proteins and their assemblies In: Biswas BB, Roy S (eds) Subcellular Biochemistry, vol. 24, Proteins: Structure, Function, and Engineering. Plenum Press, New York, pp 55-99

48. Miura T, Takeuchi H, Harada I (1989) Tryptophan Raman bands sensitive to hydrogen bonding and side-chain conformation. J Raman Spectrosc 20:667-671

49. Williams RW (1986) The secondary structure analysis using Raman amide I and amide III spectra. Method Enzymol 130:311-331

50. Dousseau F, Pézolet M (1990) Determination of the secondary structure content of proteins in aqueous solutions from their amide I and amide II infrared bands. Comparison between classical and partial least-squares methods. Biochemistry 29:8771-8779

51. Baumruk V, Pancoska P, Keiderling TA (1996) Predictions of secondary structure using statistical analyses of electronic and vibrational circular dichroism and Fourier transform infrared spectra of proteins in $\mathrm{H}_{2} \mathrm{O}$. J Mol Biol 259:774-791

52. Fabian H, Mäntele W (2002) Infrared spectroscopy of proteins. In: Chalmers JM, Griffiths PR (eds) Handbook of vibrational spectroscopy, vol. 5. Wiley, Chichester, pp $3399-3425$

53. Barth A, Zscherp C (2002) What vibrations tell us about proteins. Q Rev Biophys $35: 369-430$ 
54. Barth A (2000) The infrared absorption of amino acid side chains. Prog Biophys Mol Biol 73:1-49

55. Miura T, Takeuchi H, Harada I (1988) Characterization of individual tryptophan side chains in proteins using Raman spectroscopy and hydrogen-deuterium exchange kinetics. Biochemistry 27:88-94

56. Siamwiza MN, Lord RC, Chen MC (1975) Interpretation of the doublet at 850 and 830 $\mathrm{cm}^{-1}$ in the Raman spectra of tyrosyl residues in proteins and certain model compounds. Biochemistry 14:4870-4876

57. Noda I (1990) Two-dimensional infrared (2D IR) spectroscopy: Theory and applications. Appl Spectrosc 44:550-561

58. Noda I (1993) Generalized two-dimensional correlation method applicable to infrared, Raman, and other types of spectroscopy. Appl Spectrosc 47:1329-1336

59. Noda I, Ozaki Y (2004) Two-dimensional correlation spectroscopy: Applications in vibrational and optical spectroscopy. Wiley, Chichester

60. Miura T, Takeuchi H, Harada I (1991) Raman spectroscopic characterization of tryptophan side chains in lysozyme bound to inhibitors: Role of the hydrophobic box in the enzimatic function. Biochemistry 30:6074-6080

61. Weis WI, Taylor ME, Drickamer K (1998) The C-type lectin like superfamily in the immune system. Immunol Rev 163:19-34

62. Pompach P, Man P. Kavan D et al (2009) Modified electrophoretic and digestion conditions allow a simplified mass spectrometric evaluation of disulfide bonds. Journal of Mass Spectrometry 44: 1571-1578

63. Kabsch W, Sander C (1985) Identical pentapeptides with different backbones. Nature $317: 19-25$

64. Sternberg MJE, Islam SA (1990) Local protein sequence similarity does not imply a structural relationship. Protein Eng 4:125-131

65. Kopecký V Jr, Ettrich R, Hofbauerová K, Baumruk V (2004) Vibrational spectroscopy and computer modeling of proteins: solving structure of $\alpha_{1}$-acid glycoprotein. Spectrosc Int J 18:323-330 


\section{Tables}

Table 1 Protein and nucleotide sequences used for phylogenetic and sequence analyses

\begin{tabular}{|c|c|c|c|}
\hline protein & $\begin{array}{l}\text { protein sequence } \\
\text { ABO15817 }\end{array}$ & $\begin{array}{l}\text { DNA sequence } \\
\text { EF100677 }\end{array}$ & $\begin{array}{l}\text { Reference } \\
\text { Voigt et al., } 2007 \text { [9] }\end{array}$ \\
\hline rNKR-P1A & & & \\
\hline SD & ABO15823 & EF100683 & Voigt et al., 2007 [9] \\
\hline rNKR-P1A & & & \\
\hline RNK & ABO15821 & EF100681 & Voigt et al., 2007 [9] \\
\hline rNKR-P1A & & & \\
\hline rNKR-P1A $^{\text {F344 }}$ & AAA41710 & M62891 & Giorda et al, 1990 [10] \\
\hline PVG & ACJ47804 & FJ416340 & Kveberg et al., 2009 [11] \\
\hline rNKR-P1A & & & \\
\hline WAG & ABO15818 & EF100678 & Voigt et al., 2007 [9] \\
\hline $\begin{array}{l}\text { rNKR-P1B } \\
\text { BS }\end{array}$ & AAO08908 & AF525533 & Voigt et al., 2007 [9] \\
\hline rNKR-P1B & & & \\
\hline PVG & ABA40404 & NM_001040189 & Voigt et al., 2007 [9] \\
\hline SD & $\mathrm{ABO} 15824$ & EF100684 & Voigt et al., 2007 [9] \\
\hline $\begin{array}{l}\text { RNKR-PIB } \\
\text { RNK }\end{array}$ & $\mathrm{ABO} 15822$ & EF100682 & Voigt et al., 2007 [9] \\
\hline $\begin{array}{l}\text { rNKR-P1B } \\
\text { F344 }\end{array}$ & AAB01986 & U56936 & Dissen et al., 1996 [12] \\
\hline $\begin{array}{l}\text { rNKR-P1B } \\
\text { TO } \\
\text { rNKR-P1B }\end{array}$ & AAQ11375 & AF541943 & Voigt et al., 2007 [9] \\
\hline rNKR-P1F & ABO15819 & EF100679 & Voigt et al., 2007 [9] \\
\hline rNKR-P1F & ABO15825 & EF100685 & Voigt et al., 2007 [9] \\
\hline F344 & CAA66111 & X97477 & Appasamy et al., 1996 [13 \\
\hline rNKR-P1G & $\mathrm{ABO} 15820$ & EF100680 & Voigt et al., 2007 [9] \\
\hline rNKR-P1G & ABA40405 & DQ157011 & Kveberg et al., 2009 [11] \\
\hline $\begin{array}{l}\text { rNKR-PIG } \\
\text { DA } \\
\text { rNKR-P1G }\end{array}$ & ABA40406 & DQ157012 & Kveberg et al., 2009 [11] \\
\hline mNKR-P1A & AAA39822 & M77676 & Giorda et al., 1991 [14] \\
\hline$m^{\text {BALB }}$ & ABB72025 & DQ237927 & Carlyle et al., 2006 [15] \\
\hline mNKR-P1A & AAK39101 & AF354261 & Kung et al., 1999 [16] \\
\hline mNKR-P1B & AAK08512 & AF338321 & Carlyle et al., 2006 [15] \\
\hline mNKR-P1B & AAK39099 & AF354259 & Kung et al., 1999 [16] \\
\hline mNKR-P1B $^{\text {NOD }}$ & BAE41390 & AK169820 & Carninci et al., 1999 [17] \\
\hline mNKR-P1B & ABB72026 & DQ23728 & Carlyle et al., 2006 [15] \\
\hline$m^{2}{ }^{\text {B6 } 6}$ & BAC37739 & AK079743 & Carninci et al., 1999 [17] \\
\hline
\end{tabular}


24

\begin{tabular}{|c|c|c|c|}
\hline \multirow{2}{*}{\multicolumn{4}{|c|}{$m_{\text {mKR-P1C }}^{\text {BALB }}$}} \\
\hline & & & \\
\hline B6 & NP_694734 & NM_153094 & Plougastel et al., 2001 [18] \\
\hline mNKR-P1F & & & \\
\hline BALB & ABB72029 & DQ237931 & Carlyle et al., 2006 [15] \\
\hline mNKR-P1F & & & \\
\hline NOD & BAE41516 & AK170023 & Carninci et al., 1999 [17] \\
\hline mNKR-P1F & & & \\
\hline B6 & ABC71751 & DQ336141 & Carlyle et al., 2006 [15] \\
\hline mNKR-P1G & & & \\
\hline hNKP-P & NP_002249 & NM_002258 & Lanier et al., 1994 [19] \\
\hline & CAB55571 & AJ245903 & Kaufman et al., 1999 [20] \\
\hline
\end{tabular}


Table 2 The assignment of Raman vibrational bands distinguishable in the spectra of rat NKR-P1A protein (see Fig. 4)

\begin{tabular}{|c|c|c|}
\hline Frequency $\left(\mathrm{cm}^{-1}\right)$ & Assignment & Notes \\
\hline 509 & $\nu \mathrm{S}-\mathrm{S}$ in GGG & [44] \\
\hline 539 & $v \mathrm{~S}-\mathrm{S}$ in TGT & [44] \\
\hline 572 & Trp & [44] \\
\hline 623 & Phe & {$[45,46]$} \\
\hline 642 & Tyr & {$[45,46]$} \\
\hline 697 & $v \mathrm{C}-\mathrm{S} \mathrm{P}_{\mathrm{N}}, \mathrm{P}_{\mathrm{H}}$ & [44] \\
\hline 760 & Trp W18 & [45-47] \\
\hline 828 & Tyr doublet, Phe & [44-47] \\
\hline 853 & Tyr doublet, Ile & [44-47] \\
\hline 878 & Trp W17, Ile, Val & {$[45-47]$} \\
\hline 894 & Lys, Ala & {$[45,46]$} \\
\hline 937 & Lys, Val, Leu & {$[45,46]$} \\
\hline 959 & Lys, Leu & {$[45,46]$} \\
\hline 988 & Ile & {$[45,46]$} \\
\hline 1005 & Phe & [44-46] \\
\hline 1011 & Trp W16 shoulder & [44-47] \\
\hline 1033 & Phe, Tyr & [44-46] \\
\hline 1062 & Lys, Ala, Phe & {$[45,46]$} \\
\hline 1077 & Lys, Phe & {$[45,46]$} \\
\hline 1127 & Ile, Val, Leu, Trp & {$[45,46]$} \\
\hline 1158 & Ile, Val & {$[45,46]$} \\
\hline 1175 & Tyr, Phe & {$[45,46]$} \\
\hline 1206 & Phe, Tyr, Trp shoulder & {$[45,46]$} \\
\hline 1237 & amide III & {$[45,46]$} \\
\hline 1315 & amide III, Lys, Val, Ile & {$[45,46]$} \\
\hline 1339 & Trp doublet & [44-47] \\
\hline 1358 & Trp doublet, Val, Phe & [44-47] \\
\hline 1404 & $v \mathrm{CO}_{2}^{-}$of Asp, Glu & [47] \\
\hline 1425 & Trp shoulder & {$[45,46]$} \\
\hline 1449 & $\delta \mathrm{CH}_{2}, \delta \mathrm{CH}_{3}$, Lys, Ile, Leu & {$[45,46]$} \\
\hline 1462 & $\delta \mathrm{CH}_{2}$, Ala, Ile, Val, Leu, Trp, Tyr & {$[45,46]$} \\
\hline 1551 & Trp W3 & [48] \\
\hline 1579 & Trp, Phe & {$[45,46]$} \\
\hline 1607 & Phe, Tyr Y8b & {$[45-47]$} \\
\hline 1620 & Tyr Y8a, Trp & [45-47] \\
\hline 1671 & amide I & [44-47] \\
\hline
\end{tabular}


Table 3 An estimation of secondary structure content of mNKR-P1A/C and rNKR-P1A/B proteins in aqueous solution by pattern recognition least-squares method (LSA) analyzing the amide I band in the case of Raman spectroscopy [49], and amide I and II region in the case of FTIR [50] (using the spectral set from ref. [51]). Secondary structure estimation is compared with modeled structures. Given standard deviations are calculated as standard deviations of the used reference set, therefore they do not reflect the quality of the fits

\begin{tabular}{lllllll} 
& \multicolumn{2}{l}{ mouse NKR-P1A } & \multicolumn{4}{l}{ mouse NKR-P1C } \\
Structure & Raman & FTIR & Model & Raman & FTIR & Model \\
$\alpha$-helix & $28 \pm 5$ & $22 \pm 10$ & 15 & $26 \pm 5$ & $20 \pm 10$ & 20 \\
$\beta$-sheet & $38 \pm 4$ & $26 \pm 9$ & 39 & $37 \pm 4$ & $24 \pm 9$ & 37 \\
$\beta$-turn & $17 \pm 2$ & $14 \pm 4$ & 10 & $18 \pm 2$ & $14 \pm 4$ & 14 \\
$\beta$-bend & - & $14 \pm 4$ & 18 & - & $18 \pm 4$ & 10 \\
Unordered & $17 \pm 2$ & $24 \pm 6$ & 18 & $19 \pm 2$ & $24 \pm 6$ & 19 \\
& rat NKR-P1A & & rat NKR-P1B & \\
Structure & Raman & FTIR & Structure & Raman & FTIR & Structure \\
$\alpha$-helix & $15 \pm 5$ & $13 \pm 10$ & 18 & $19 \pm 5$ & $25 \pm 10$ & 25 \\
$\beta$-sheet & $50 \pm 4$ & $32 \pm 9$ & 40 & $48 \pm 4$ & $26 \pm 9$ & 33 \\
$\beta$-turn & $19 \pm 2$ & $13 \pm 4$ & 15 & $19 \pm 2$ & $10 \pm 4$ & 12 \\
$\beta$-bend & - & $16 \pm 4$ & 11 & - & $14 \pm 4$ & 12 \\
Unordered & $15 \pm 2$ & $26 \pm 6$ & 16 & $14 \pm 2$ & $25 \pm 6$ & 18
\end{tabular}


Table 4 Amino acids (their primary structure number) that form $\alpha$-helices or $\beta$-strands in every model that was calculated in Procheck. In mouse NKR-P1F, $\beta$-strand 4 is divided into two regions. For this reason there are two numbers in the relevant column

\begin{tabular}{llllllllllll} 
& I & II & A & III & B & IV & C & V & VI & VII & VIII \\
Mouse A & $100-$ & $104-$ & $119-$ & $129-$ & $135-$ & $152-$ & & $167-$ & $188-$ & $197-$ & $207-$ \\
& 102 & 114 & 127 & $131-146$ & 159 & & 169 & 194 & 203 & 215 \\
Rat A & $97-101$ & $103-$ & $114-$ & $128-$ & $134-$ & $150-$ & & $164-$ & $188-$ & $196-$ & $206-$ \\
& & 113 & 125 & $130-145$ & 159 & & 168 & 194 & 200 & 215 \\
Rat B & $100-$ & $104-$ & $115-$ & $129-131$ & $135-$ & $152-$ & $175-$ & 182,183 & $190-$ & $197-$ & $207-$ \\
& 102 & 114 & 126 & & 149 & 155 & 181 & & 194 & 201 & 215 \\
Mouse C & $100-$ & $104-$ & $115-$ & $129-$ & $135-$ & $152-$ & & $167-$ & $188-$ & $197-$ & $207-$ \\
& 102 & 114 & 126 & 131 & 149 & 159 & & 169 & 194 & 201 & 215 \\
Mouse F & $98-102$ & $105-$ & $115-$ & $129-$ & $135-$ & $152-$ & & $167-$ & $190-$ & $199-$ & $207-$ \\
& & 114 & 126 & 131 & 146 & $154 / 156$ & 169 & 192 & 201 & 213 \\
& & & & & & -158 & & & & & \\
\multirow{2}{*}{ Mouse G } & $98-102$ & $104-$ & $115-$ & $129-$ & $135-$ & $152-$ & & $167-$ & $188-$ & $197-$ & $207-$ \\
& & 114 & 126 & 131 & 146 & 159 & & 169 & 194 & 203 & 215 \\
Human & $98-102$ & $105-$ & $116-$ & $129-$ & $135-$ & $153-$ & $175-$ & $165-$ & $189-$ & $197-$ & $205-$ \\
& & 115 & 125 & 131 & 147 & 160 & 180 & 169 & 194 & 201 & 213
\end{tabular}


Table 5 The number of residues in secondary structure features. In mouse NKR-P1F, $\beta$ strand 4 is divided into two regions. For this reason there are two numbers in the relevant column

$\begin{array}{llllllllllll} & 1 & 2 & \text { A } & 3 & \text { B } & 4 & \text { C } & 5 & 6 & 7 & 8 \\ \text { Mouse A } & 2 & 11 & 9 & 3 & 12 & 8 & & 3 & 7 & 7 & 9 \\ \text { Rat A } & 5 & 11 & 12 & 3 & 12 & 10 & & 5 & 6 & 5 & 9 \\ \text { Rat B } & 3 & 11 & 11 & 3 & 12 & 4 & 7 & 2 & 5 & 4 & 9 \\ \text { Mouse C } & 3 & 11 & 12 & 3 & 15 & 8 & & 3 & 6 & 5 & 9 \\ \text { Mouse F } & 5 & 10 & 12 & 3 & 12 & 3+3 & & 3 & 3 & 3 & 7 \\ \text { Mouse G } & 5 & 11 & 12 & 3 & 12 & 8 & & 3 & 7 & 7 & 9 \\ \text { Human } & 5 & 11 & 10 & 3 & 13 & 8 & 6 & 5 & 6 & 5 & 9\end{array}$




\section{Figure captions}

Fig. 1 A comparison of FTIR spectra from mouse NKR-P1A protein (mA) with its mouse NKR-P1C variant $(\mathrm{mC})$ in the region of amide I and amide II bands. The dash-dot lines represents second derivative of the spectrum (smoothed by Savitski-Golay function at 15 points, i.e. ca. $14 \mathrm{~cm}^{-1}$ ). The peak positions are labeled for NKR-P1A protein. Slight shifts are therefore visible in the second derivative of FTIR NKR$\mathrm{P} 1 \mathrm{C}$ spectrum. Two major bands, observed at 1642 and $1549 \mathrm{~cm}^{-1}$, are assigned to amide I and amide II vibrations of the backbone chain, respectively. The second derivative, which can identify overlapping components, reveals a high content of extended $\beta$-sheets by a strong negative band at $1638 \mathrm{~cm}^{-1}$ [52]. The second component of $\beta$-sheets at $1688 \mathrm{~cm}^{-1}$ suggests that $\beta$-sheets are antiparallel [53]. The negative band at $1657 \mathrm{~cm}^{-1}$ corresponds to $\alpha$-helices and an unordered structure [52] which points towards an $\alpha / \beta$ protein fold. The second derivative band at $1688 \mathrm{~cm}^{-1}$, with its shoulder at $1678 \mathrm{~cm}^{-1}$, is connected with high content of loops and turns

Fig. 2 A comparison of mouse NKR-P1A DCDR spectra (mA) with its mouse NKR-P1C variant $(\mathrm{mC}) ;(\mathrm{mA}-\mathrm{mC})$ denotes appropriate spectral difference. In the amide I region at $1669 \mathrm{~cm}^{-1}$, corresponding mostly to stretching $\mathrm{vC}_{\alpha}=\mathrm{O}$ skeletal vibrations (for band assignments see Table 2), small negligible differences between mNKR$\mathrm{P} 1 \mathrm{~A}$ and $\mathrm{C}$ protein variants can be found ( $\mathrm{mA}-\mathrm{mC}$ difference). This is supported by the skeletal $\mathrm{NH}$-vibration region of amide III at $1310 \mathrm{~cm}^{-1}$, where the difference is almost zero between mouse proteins. The band at $508 \mathrm{~cm}^{-1}$ corresponds to the lowest free energy gauche-gauche-gauche (GGG) conformation of S-S bridges, the most obvious conformation in the protein structures. The band at $535 \mathrm{~cm}^{-1}$ reflects unusual conformation that is close to trans-gauche-trans - TGT (pure conformation is characterized by vibrations at $540 \mathrm{~cm}^{-1}$, whereas gauche-gauchetrans (GGT) has a band at ca. $525 \mathrm{~cm}^{-1}$ ), which has the highest free energy [44]. The intensity ratio I508 / I535 clearly indicates that two S-S bridges have GGG conformation and one nearly has TGT conformation. Direct correlation between the Raman frequency of W3 mode and the absolute value of the torsional angle $\chi^{2,1}$ is known [48]. Its position at $1550 \mathrm{~cm}^{-1}$ corresponds to a $93^{\circ}$ angle $\left|\chi^{2,1}\right|$ as an 
average angle of six Trp in mNKR-P1A/C proteins. The negative difference band at $1546 \mathrm{~cm}^{-1}$ alludes to prevalence on lower angles in the $\mathrm{C}$ variant. The Trp W17 mode at $877 \mathrm{~cm}^{-1}$ indicates moderate $\mathrm{NH}$-hydrogen bond donation in both $\mathrm{A}$ and $\mathrm{C}$ variants [55]. The Trp Fermi doublet intensity ratio I1358/I1338 ca. 0.88 is a sensitive marker of the amphipathic environment of the aromatic ring [55] and in our case indicates a hydrophilic environment of all Trp in both variants. The two bands at 827 and $852 \mathrm{~cm}^{-1}$ are assigned to the Tyr (Y1+Y1a) Fermi resonance doublet. Its intensity ratio I852 / I827 is used as an Tyr environment indicator [56]. The value 1.0 of mNKR-P1A protein corresponds to moderate Tyr H-bonding, mostly at the surface of the protein. Mouse NKR-P1C protein has only one Tyr with an intensity ratio of 0.75 , which may suggest that phenolic $\mathrm{OH}$ of this Tyr is a stronger hydrogen bond donor than those placed on the surface of the protein

Fig. 3 A comparison of rat NKR-P1A FTIR spectra (rA) with its rat NKR-P1B variant $(\mathrm{rB})$ in the region of amide I and amide II bands. The dash-dot lines represents second derivative of the spectrum (smoothed by Savitski-Golay function at 15 points, i.e. ca. $21 \mathrm{~cm}^{-1}$ ). Although the rNKR-P1B spectrum was partially affected by the low stability of the sample which caused partial aggregation (resolved by second derivative bands at 1623 and $1693 \mathrm{~cm}^{-1}$ ) [52], higher amounts of helical structures (second derivative band at $1654 \mathrm{~cm}^{-1}$ ) in comparison with antiparallel $\beta$ sheets (negative bands at 1638 and shoulder at $1682 \mathrm{~cm}^{-1}$ ) can be seen

Fig. 4 A comparison of rat NKR-P1A DCDR spectra (rA) with its rat NKR-P1B variant $(\mathrm{rB}) ;(\mathrm{rA}-\mathrm{rB})$ denotes appropriate spectral difference. It is clearly visible in the disulfide bridges stretching vibrations region (the bands at 509 and $539 \mathrm{~cm}^{-1}$ ), that two $\mathrm{S}-\mathrm{S}$ bridges are in GGG conformation whereas one is in pure TGT conformation. In comparison with mouse protein $\mathrm{A} / \mathrm{C}$ variants, rat variants show a higher tension on this TGT bridge. The $\mathrm{S}-\mathrm{S}$ bridges in rNKR-P1B are much more flexible than in the A variant (exhibiting broader and less intense bands) which points to a lower stability of this protein. Only small differences exist between all mouse and rat proteins when comparing the absolute value of the torsional angle $\chi^{2,1}$ that is characterized by the band at $1551 \mathrm{~cm}^{-1}$, which corresponds to an average $95^{\circ}$ angle of six Tyr. Nevertheless, there is a positive peak, also visible within the Raman difference spectra, that is reflecting higher flexibility in the rNKR-P1B 
protein. In the case of mouse $\mathrm{A} / \mathrm{C}$ variants, other prominent Tyr bands $(878,1339$, $1358 \mathrm{~cm}^{-1}$ ) reflect the same phenomena as mentioned above whereas each of these vibrations shows higher flexibility in the rNKR-P1B protein. The rat proteins have only one Tyr whose ratio 1.0 of 828 and $853 \mathrm{~cm}^{-1}$ bands corresponds to moderate H-bonding which is characteristic for the position on the protein surface.

Fig. 5 Synchronous (left) and asynchronous (right) 2D correlation FTIR spectra of thermal dynamics from $5{ }^{\circ} \mathrm{C}$ to $90{ }^{\circ} \mathrm{C}$ (with $5{ }^{\circ} \mathrm{C}$ increments) of mouse NKR-P1A (mA) and NKR-P1C $(\mathrm{mC})$ proteins. The white and red peaks are positive while the grey and blue peaks are negative. The synchronous second derivative $2 \mathrm{DCoS}$ spectra from FTIR spectra of mNKR-P1A/C, under thermal perturbation from $5{ }^{\circ} \mathrm{C}$ to $90{ }^{\circ} \mathrm{C}$, exhibit several positive diagonal peaks, so called autopeaks (see left side). The diagonal spectrum of the synchronous $2 \mathrm{DCoS}$ mathematically corresponds to autocorrelation function. Thus, any region of the spectrum which changes intensity to a great extent, under the thermal perturbation, will show strong autopeaks, while those remaining almost constant develop no autopeaks. In the case of protein $\mathrm{mNKR}-\mathrm{P} 1 \mathrm{C}$, thermal denaturation is connected with changes of aggregate $\beta$-sheets $\left(1618 \mathrm{~cm}^{-1}\right)$, native $\beta$-sheets $\left(1635 \mathrm{~cm}^{-1}\right), \alpha$-helices and unordered structures (1646 $\left.\mathrm{cm}^{-1}\right)$, loops $\left(1668 \mathrm{~cm}^{-1}\right)$ and $\beta$-turns $\left(1685 \mathrm{~cm}^{-1}\right)$ [52] as demonstrated by its autopeaks. Synchronous $2 \mathrm{DCoS}$ describes in-phase intensity variations, i.e. structural changes, so it is questionable if the correlation is positive or negative. This question can be answered by off-diagonal peaks, so called cross peaks. While the autopeaks sign is always positive, the cross peaks sign can be either positive or negative. The synchronous cross peak sign becomes positive if the spectral intensities at the two coordinates are simultaneously increasing or decreasing. On the other hand, a negative sign at the intensity of the cross peak indicates that one of the spectral intensities is increasing while the other is decreasing. Thus, the cross peaks correspond to a simultaneous decrease of $\alpha$-helices and unordered structures with an increase of $\beta$-sheets, loops and $\beta$-turns whereas the decrease of $\beta$-sheets is then connected with the increase of $\beta$-aggregated structures. Similar structural changes can be found in synchronous FTIR 2DCoS in protein mNKR-P1A, however its transition to $\beta$-aggregates was not observable because the process was too fast 
Fig. 6 Synchronous (left) and asynchronous (right) 2D correlation Raman spectra of thermal dynamics from $5{ }^{\circ} \mathrm{C}$ to $90{ }^{\circ} \mathrm{C}$ (with $5{ }^{\circ} \mathrm{C}$ increments) of mouse NKR-P1A $(\mathrm{mA})$ and NKR-P1C $(\mathrm{mC})$ proteins. The white and red peaks are positive while the grey and blue peaks are negative. The decrease of $\alpha$-helix content (the band at $\left.1635 \mathrm{~cm}^{-1}\right)$ is connected with an increase of $\beta$-sheet and $\beta$-turn structures $\left(1685 / 1690 \mathrm{~cm}^{-1}\right.$ for mNKR-P1C and mNKR-P1A, respectively). This structural change is connected with environmental changes in Trp, Tyr and Phe residues (corresponding bands at 1590, 1600 and 1610/1625 $\mathrm{cm}^{-1}$ )

Fig. 7 Heterospectral synchronous 2D correlation analysis Raman spectra of thermal dynamics from $5{ }^{\circ} \mathrm{C}$ to $90{ }^{\circ} \mathrm{C}$ (with $5{ }^{\circ} \mathrm{C}$ increments) of mouse NKR-P1A (mA) and NKR-P1C (mC) proteins. The dynamics of two different regions against the amide I region (1580-1700 $\mathrm{cm}^{-1}$ ) was followed. The white and red peaks are positive while the grey and blue peaks are negative. An intense search through the entire Raman spectrum did reveal very strong correlations between the amide I region and Trp bands at 760 and $1011 \mathrm{~cm}^{-1}$ for both mNKR-P1 variants. It is well known that intensity changes of these Trp Raman bands are connected with amphipathic environment of the indol ring [60]. Thus, 2DCoS reflects changes in hydrophobicity in the Tyr environment by the band shifts from $756 \mathrm{~cm}^{-1}$ to $763 \mathrm{~cm}^{-}$ ${ }^{1}$ and from $1007 \mathrm{~cm}^{-1}$ to $1020 \mathrm{~cm}^{-1}$ for mNKR-P1A and similarly for mNKR-P1C. Moreover, the sign for $2 \mathrm{DCoS}$ bands is reversed in the amide I region, ca. $1690 \mathrm{~cm}^{-}$

${ }^{1}$, which corresponds to $\beta$-turn structures in proteins

Fig. 8 Alignments for homology models in the following order; mouse NKR-P1A, rat NKR-P1A, rat NKR-P1B, mouse NKR-P1C, mouse NKR-P1F, mouse NKR-P1G and human NKR-P1

Fig. 9 Detail view on the rat NKR-P1B model

Fig. 10 Structures and topologies of resultant models. The regions discussed in the text are depicted here. The same fold like mouse NKR-P1C receptor is also adopted by mouse NKR-P1A/G and rat NKR-P1A. Mouse NKR-P1F, rat NKR-P1B and human NKR-P1 folds are unique 
Fig. 11 Root mean square fluctuation of amino acid residues during the production phase of the simulation is represented by $\mathrm{C}_{\alpha}$ carbon

Fig. 12 Conserved regions among NKR-P1s and their positions in the structural model of rat NKR-P1A. A consensus secondary structure estimation is shown below the alignment in yellow. The red box indicates that a helix is present in human NKR-P1 and rat NKR-P1B only. The color scheme underlying the secondary structure indicates buried (blue) and accessible (white) residues

Fig. 13 A cladogram of all available NKR-P1s based on nucleotide sequences. If in some case different methods show either polytomy (full line) or further branching (dashed line), both are shown, however the polytomy is more relevant, the branching is only a possibility. Probability values are based on the maximum likelihood consensus tree and are displayed as percentages 


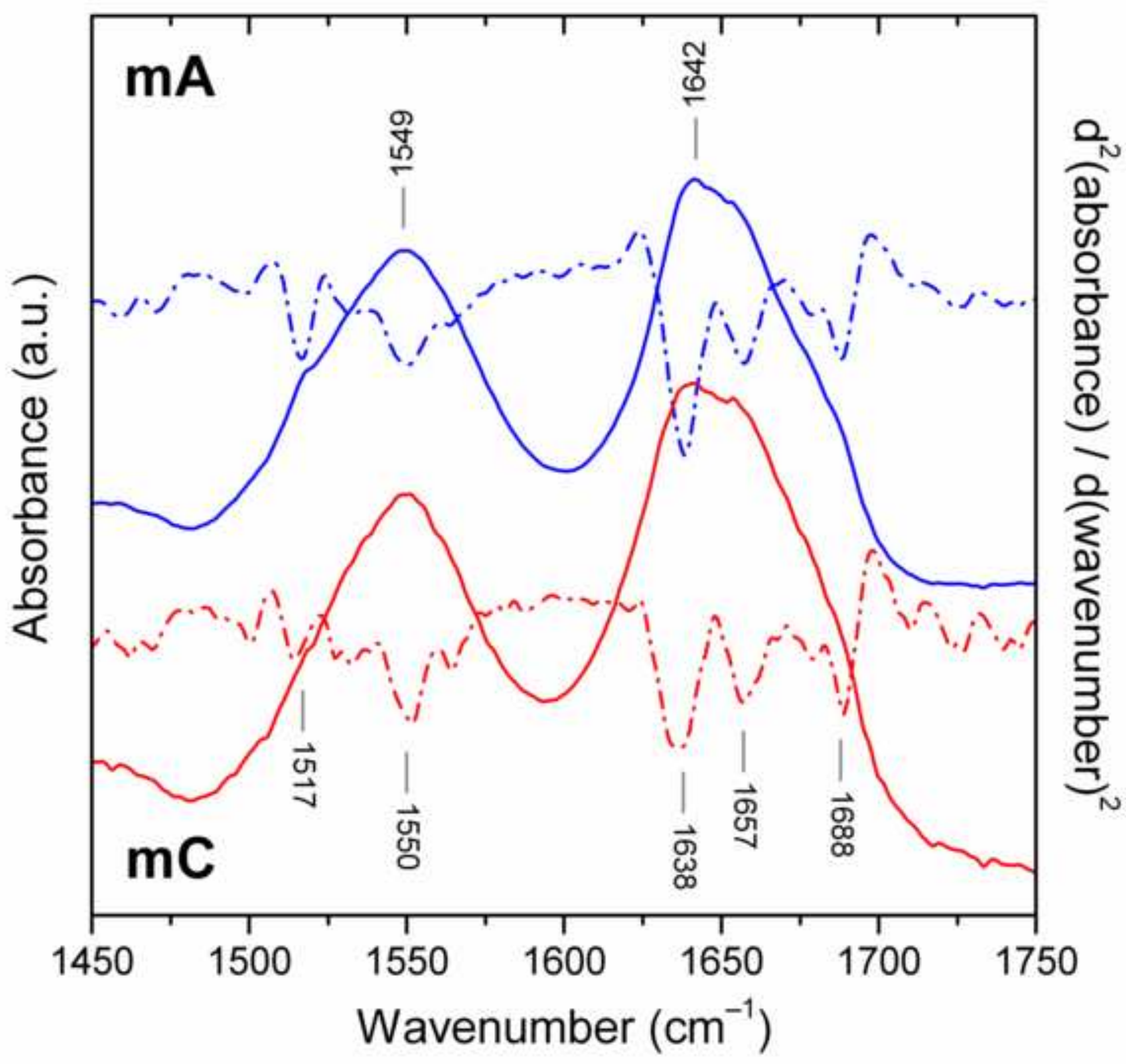




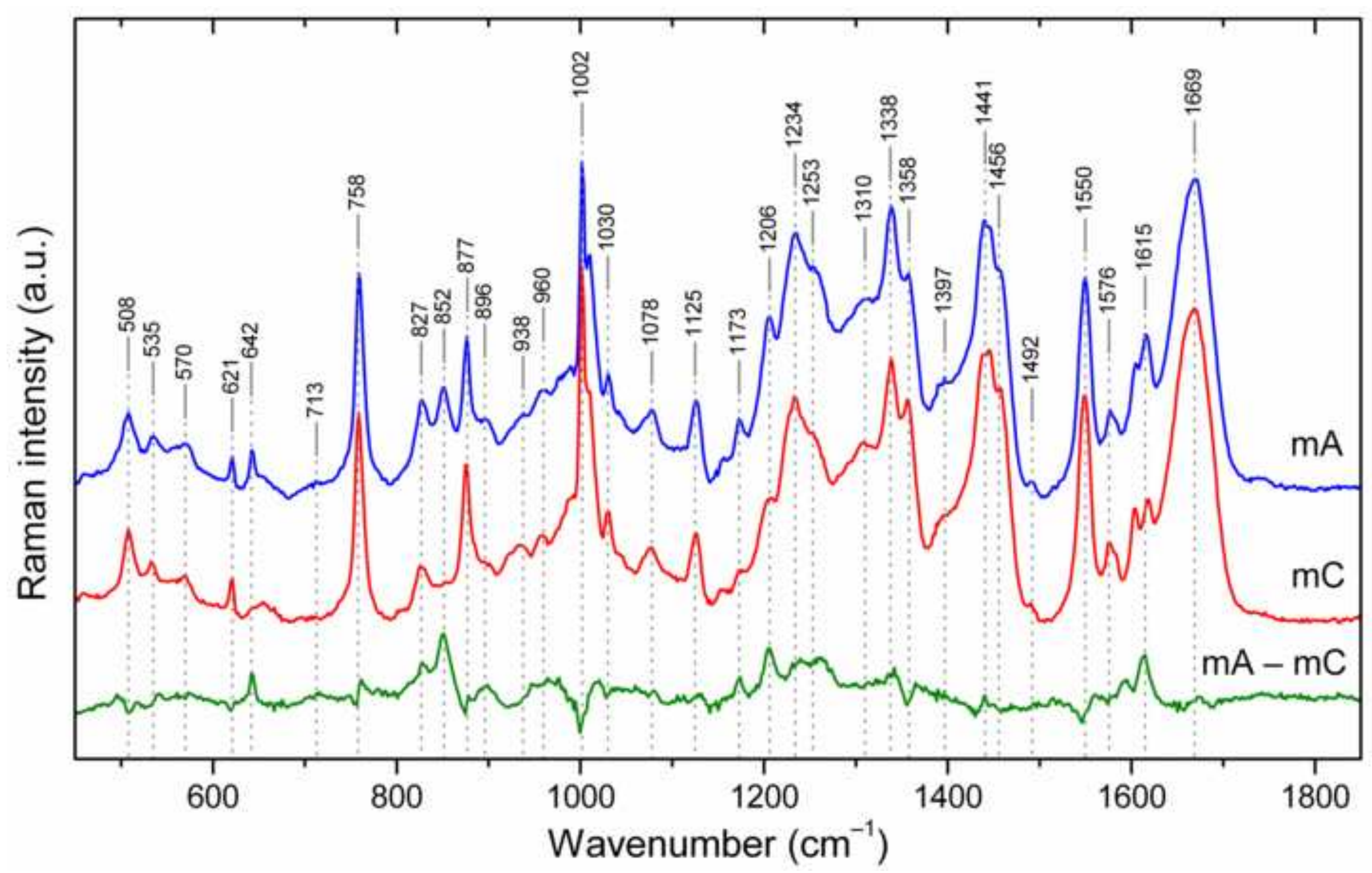




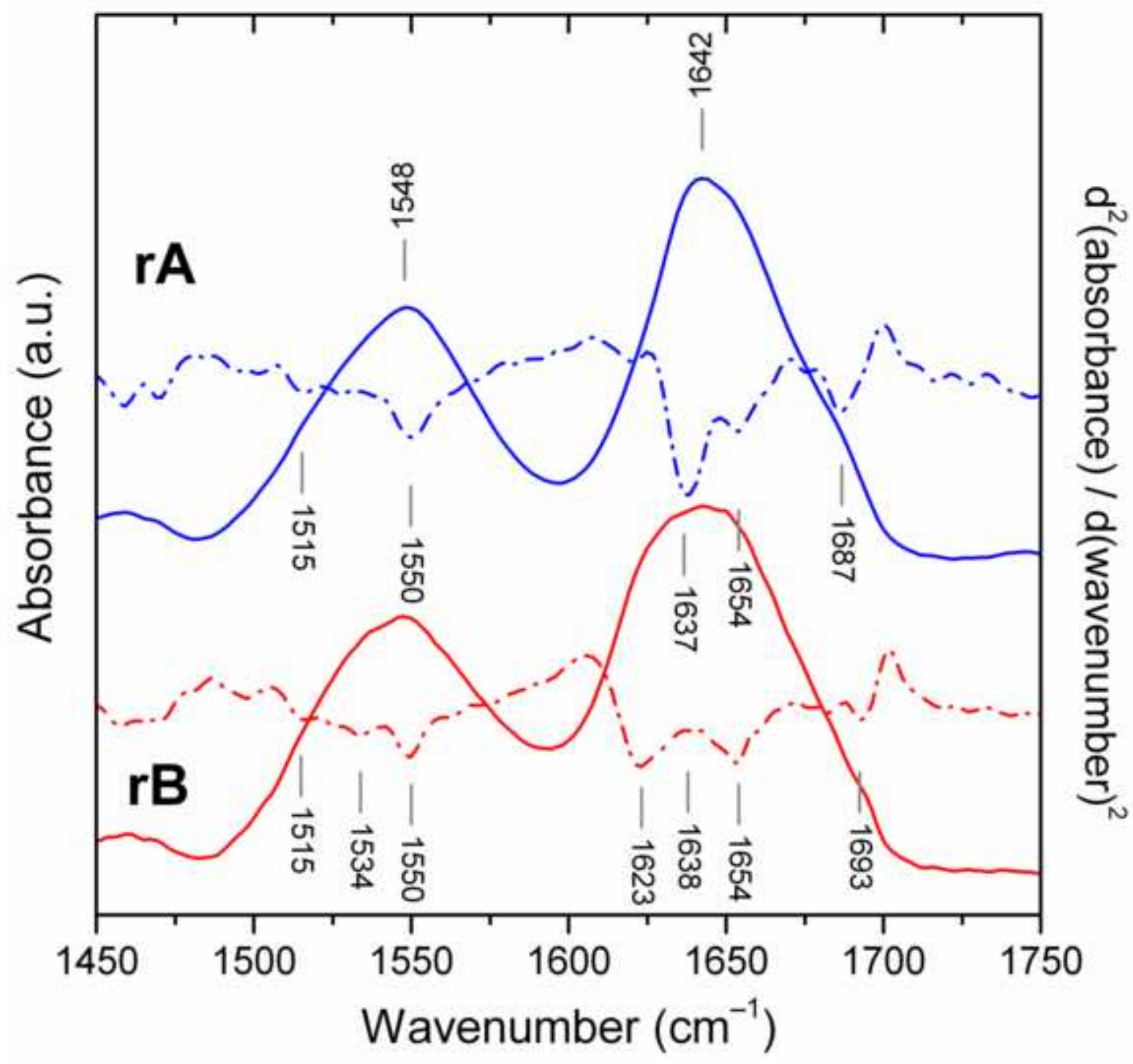




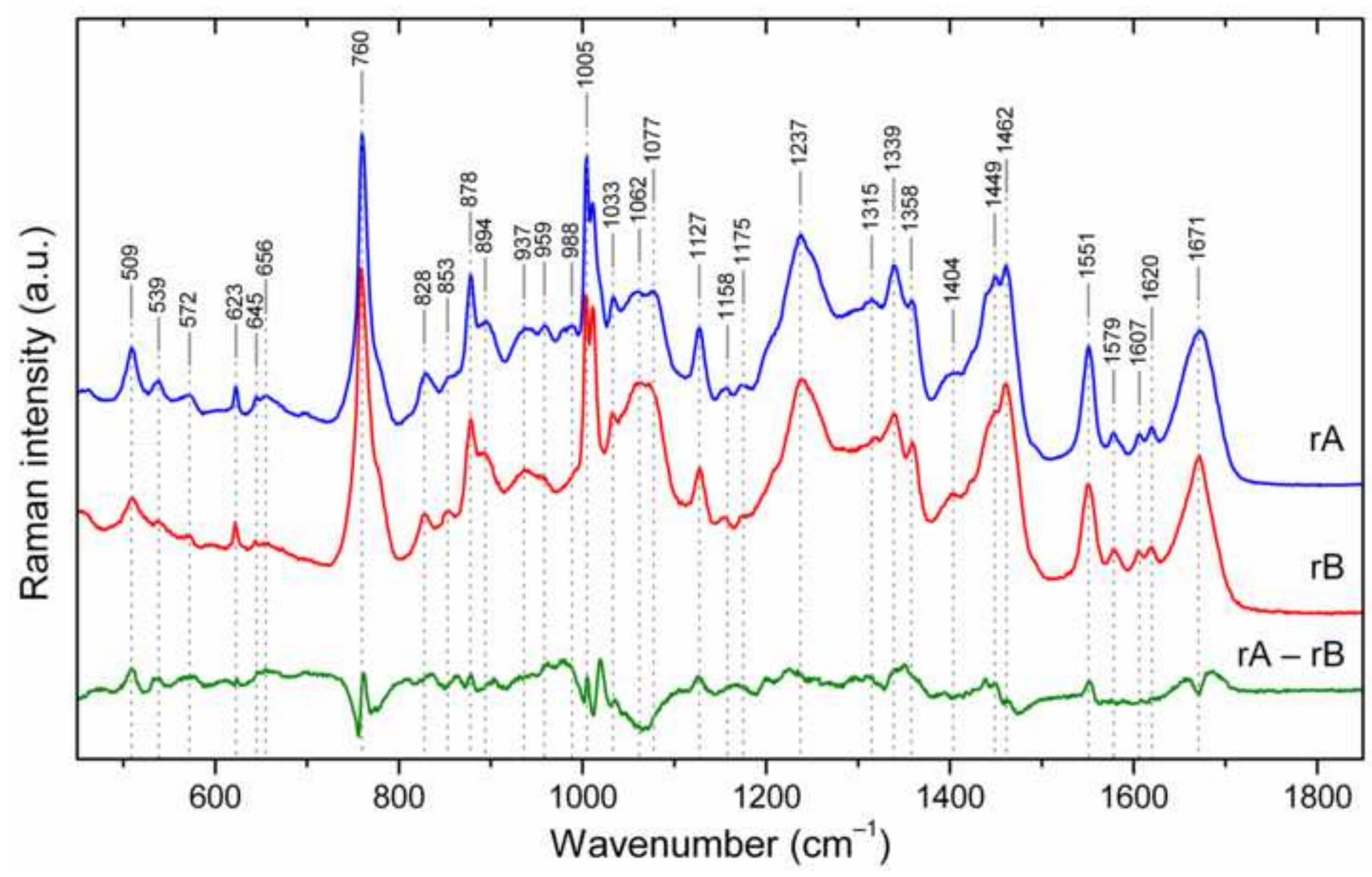




\section{Figure 5}

Click here to download high resolution image

$\mathrm{mA} \quad \stackrel{m}{\mathrm{~m}}$ \%

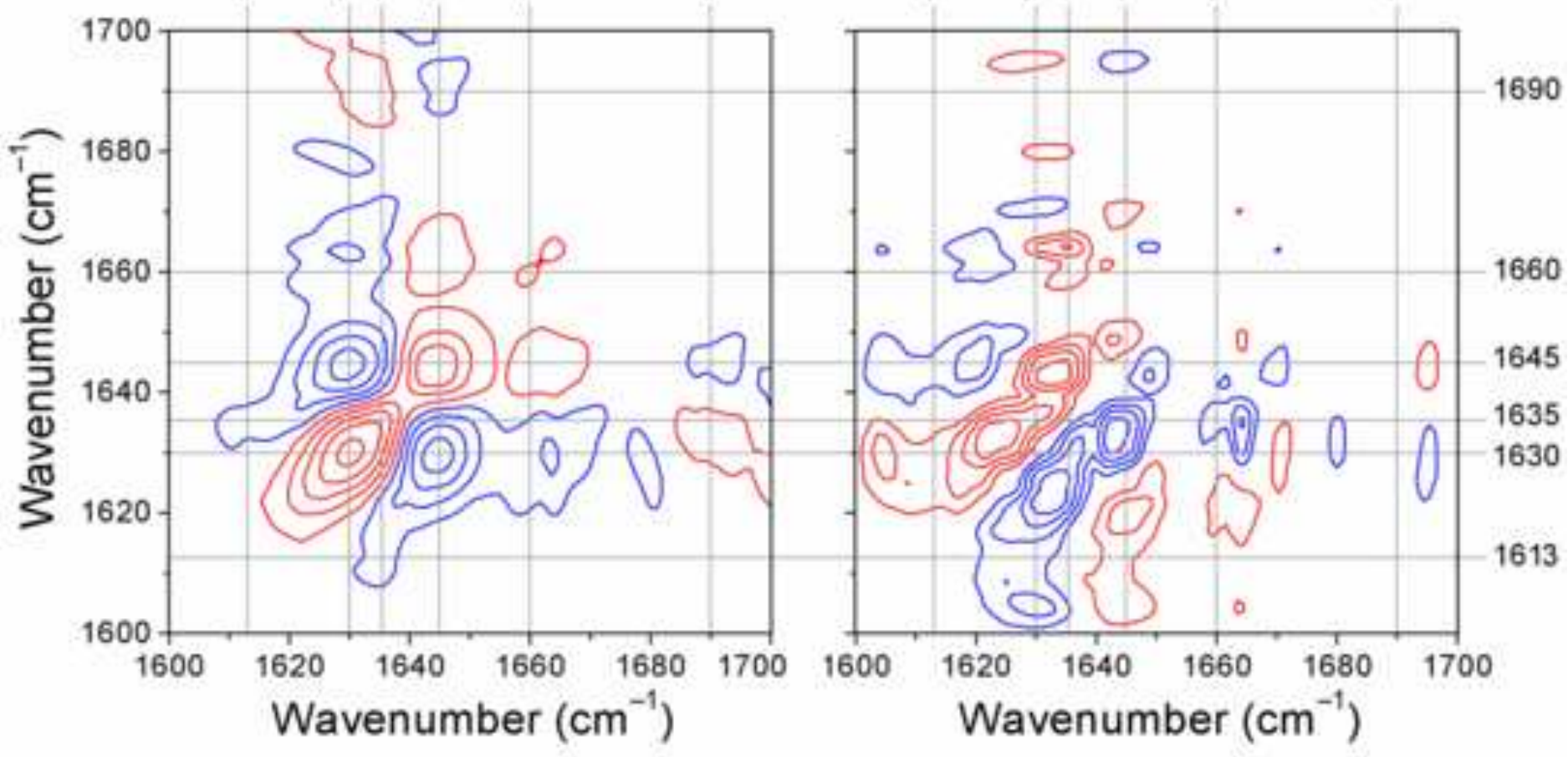

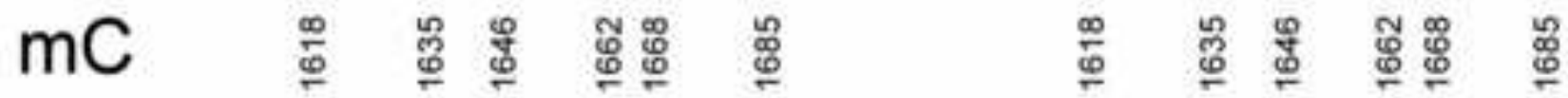

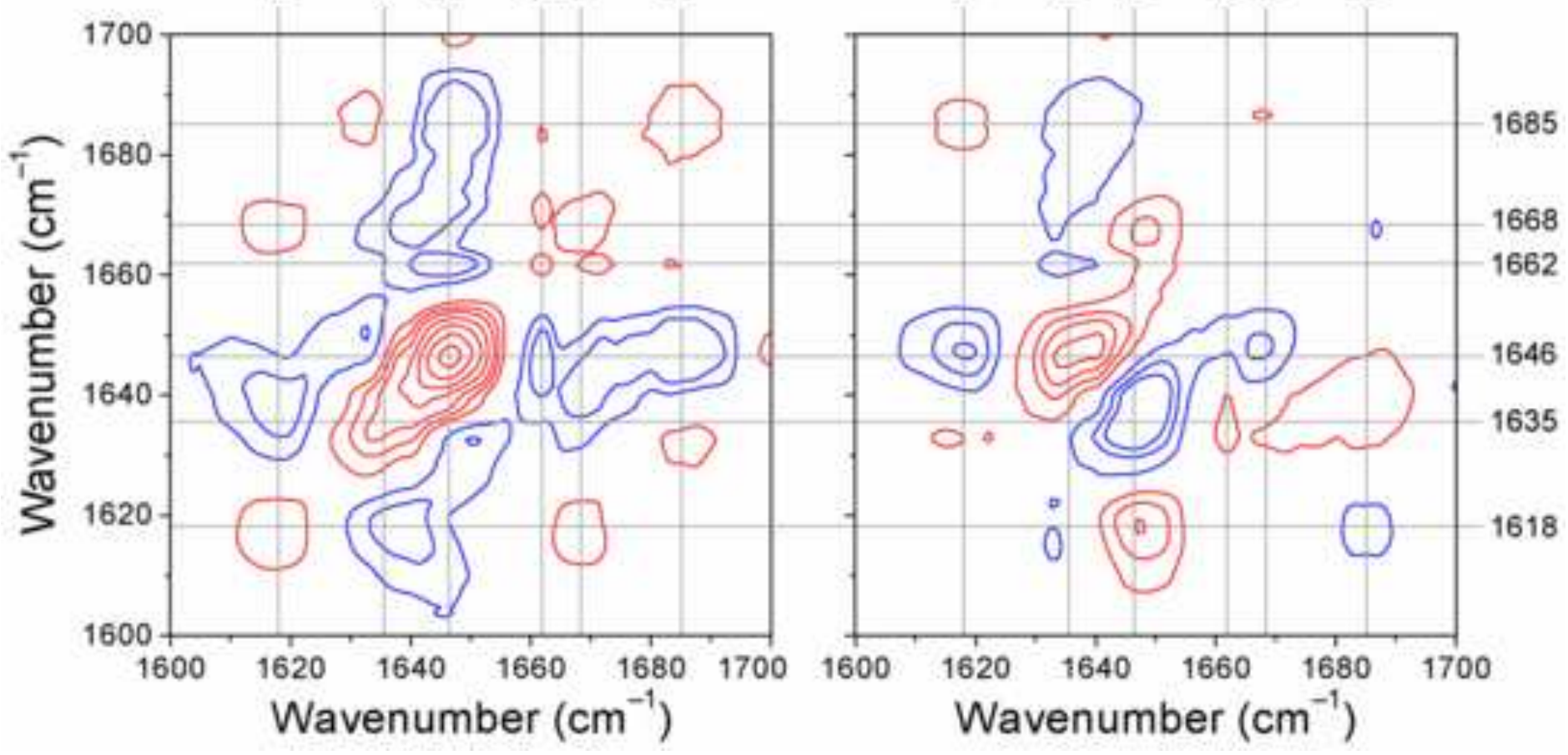




\section{Figure 6}

Click here to download high resolution image

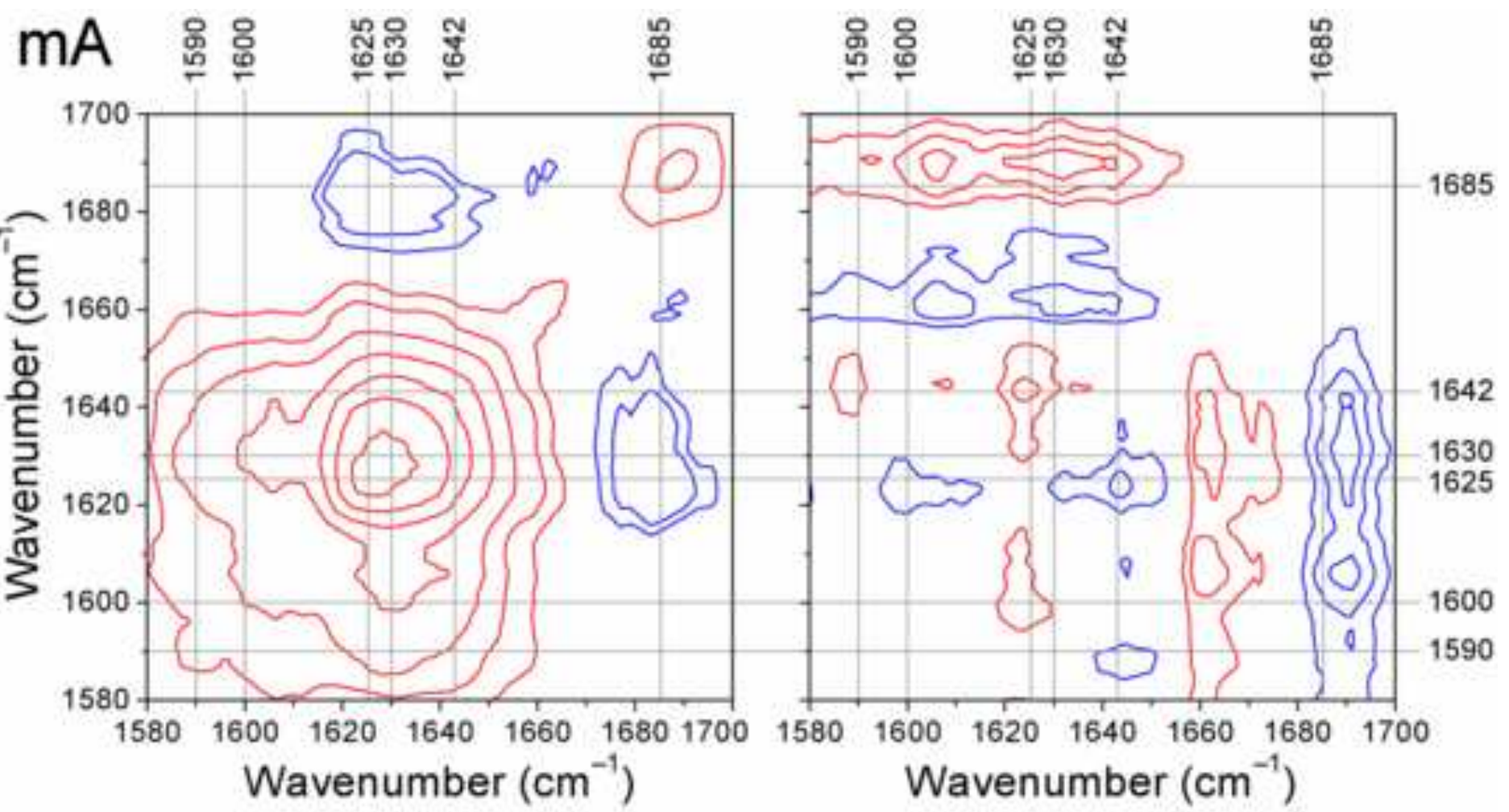

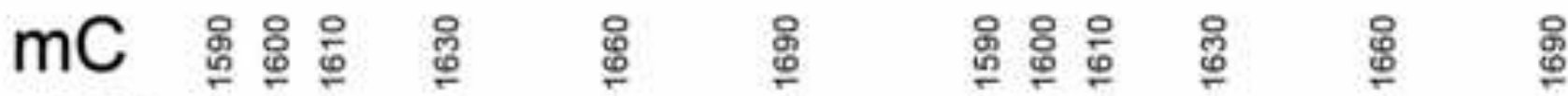

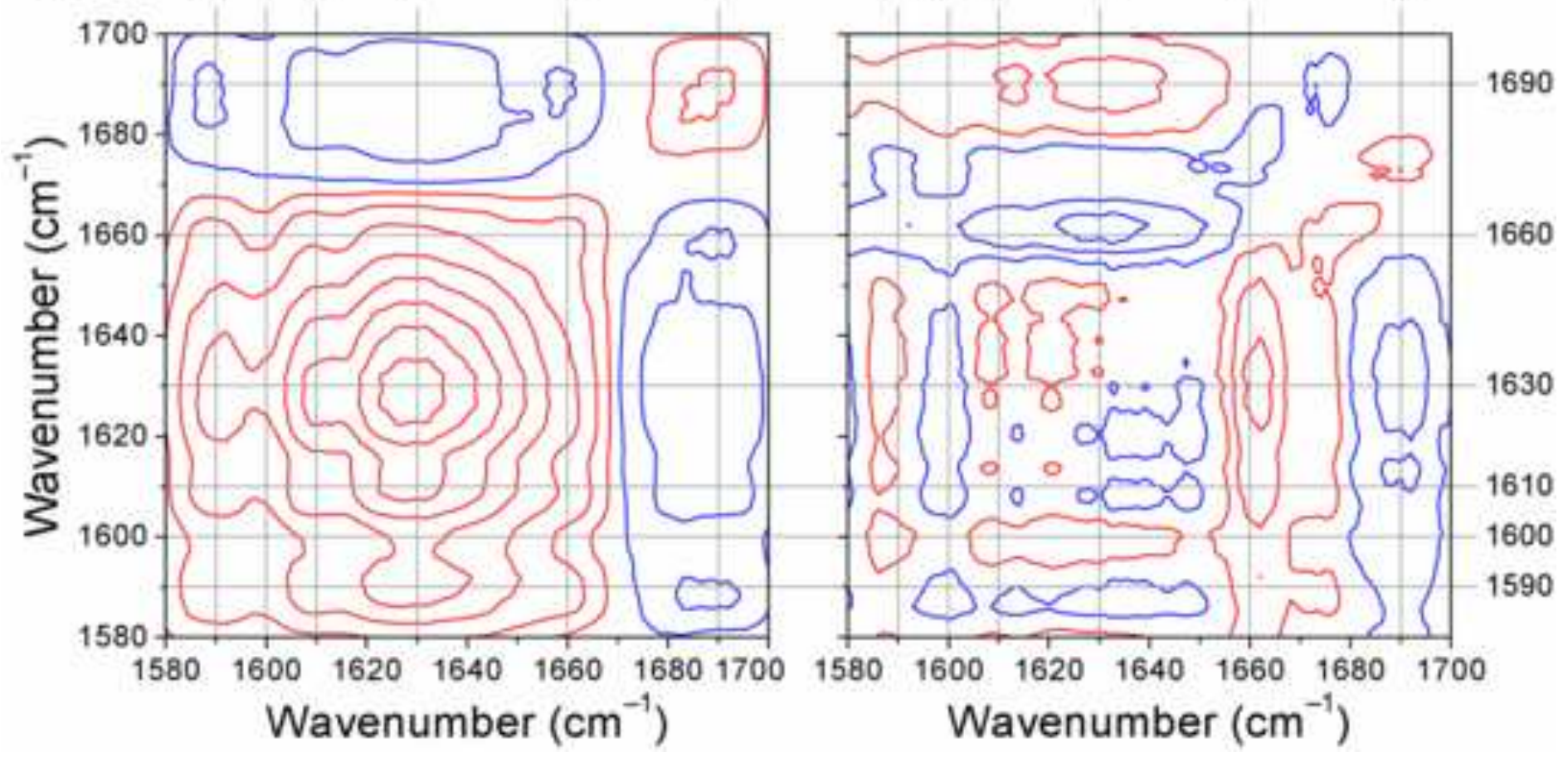




\section{Figure 7}

Click here to download high resolution image

$\mathrm{mA}$

$8:$

ธิ ฐิ
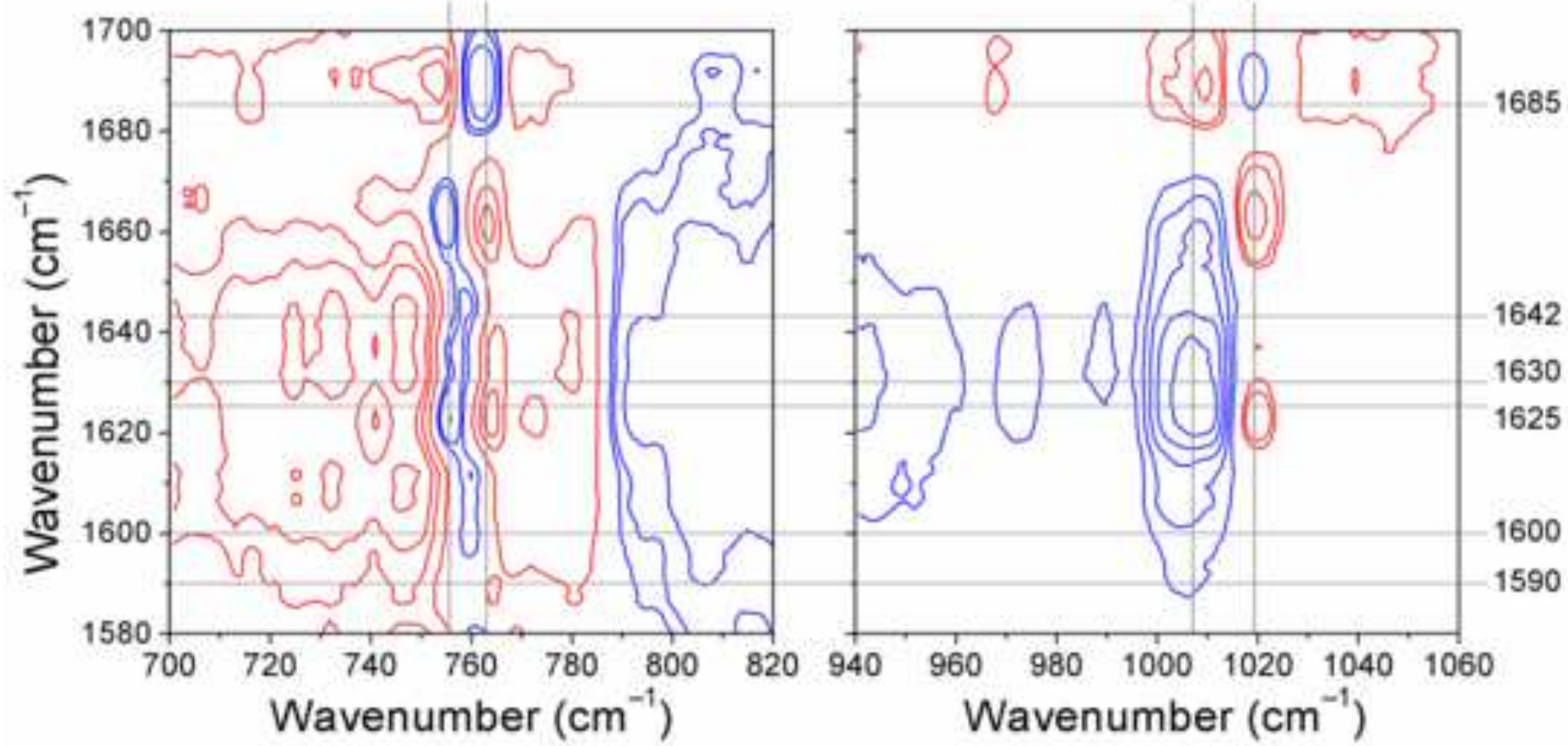

$\mathrm{mC}$

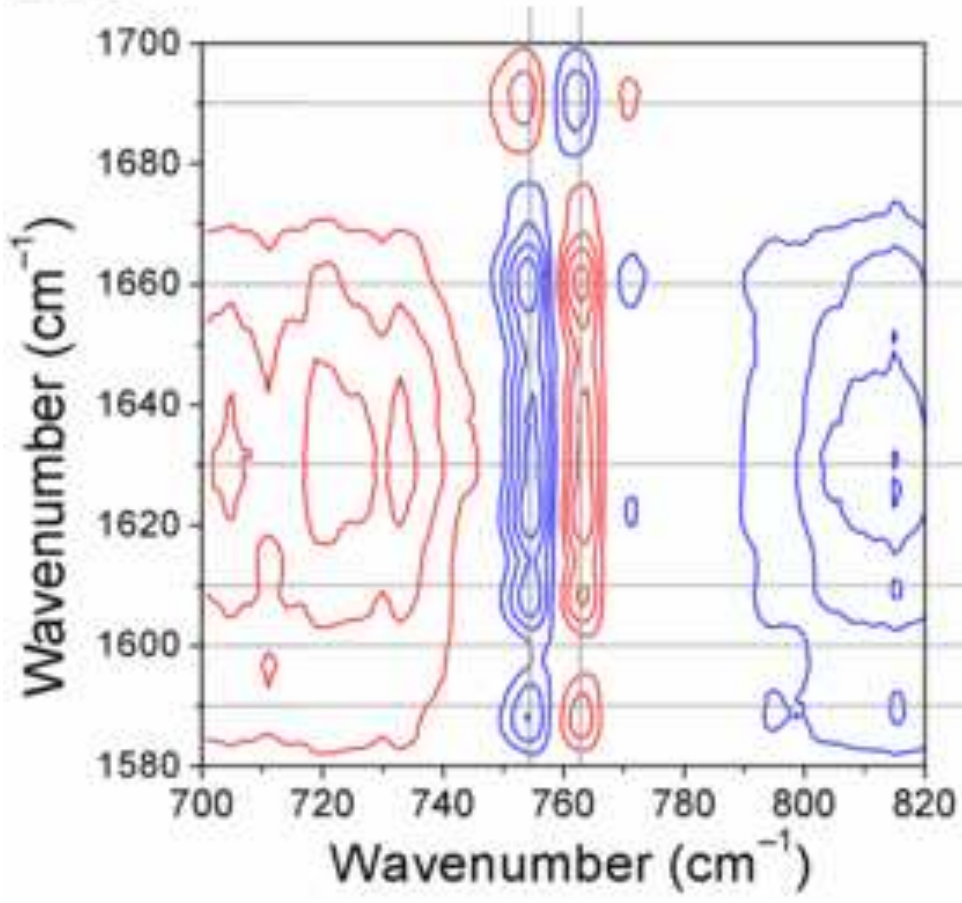

岁 :

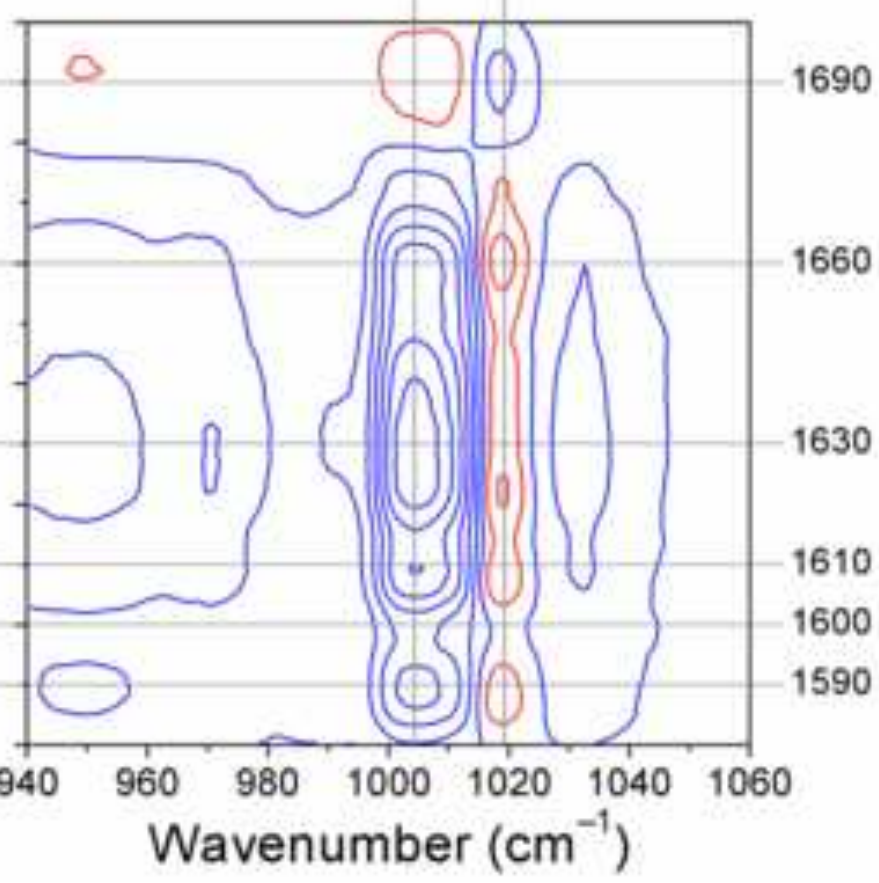




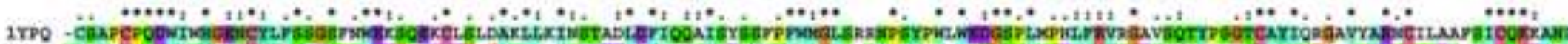

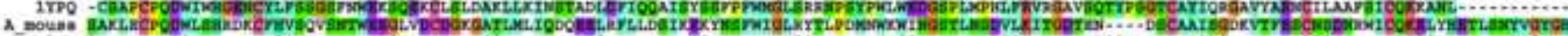

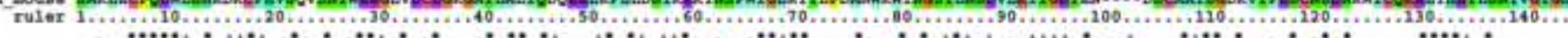

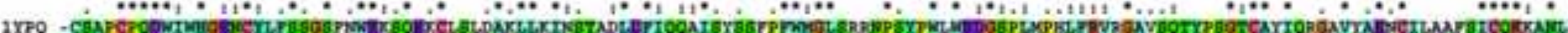

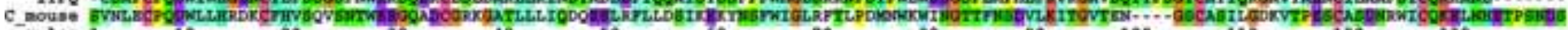

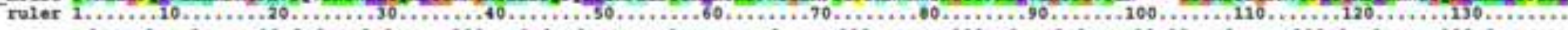
,

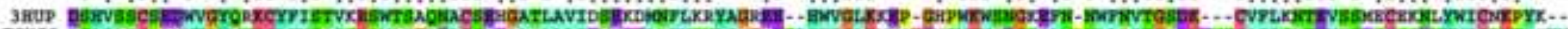

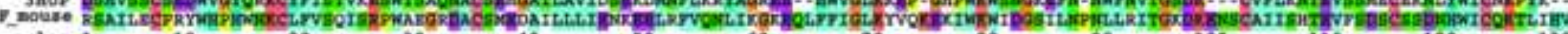

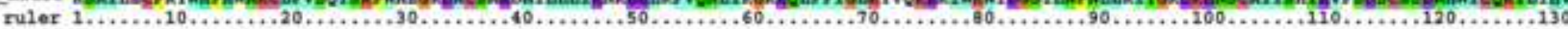

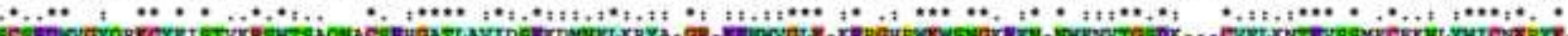

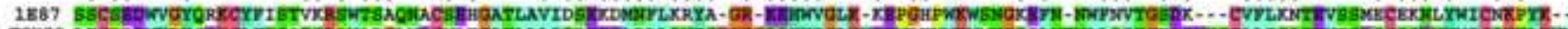

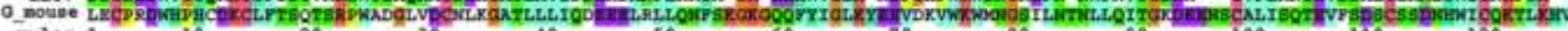

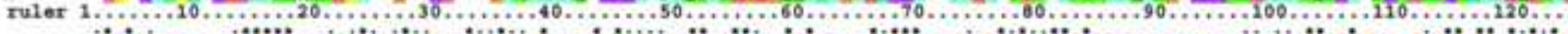

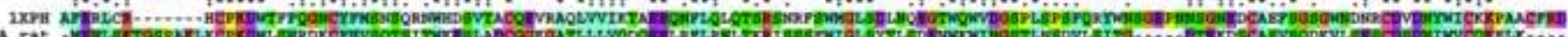

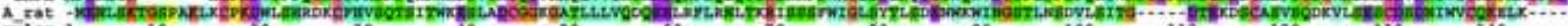

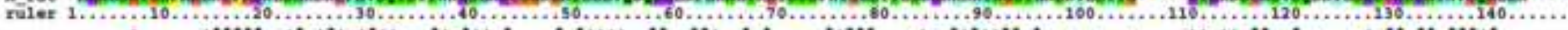

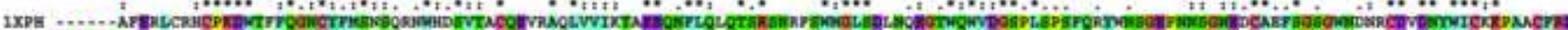

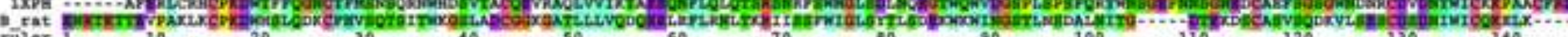

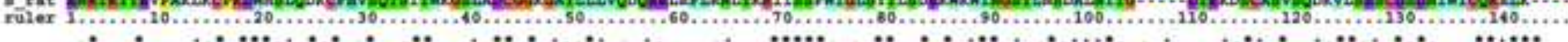

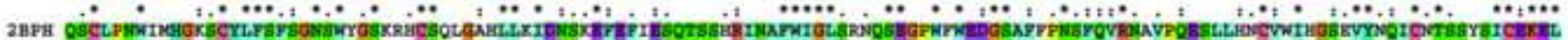

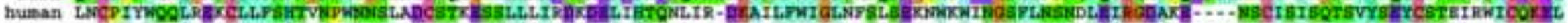

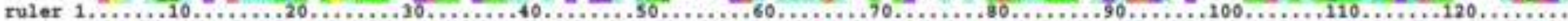


Click here to download high resolution image

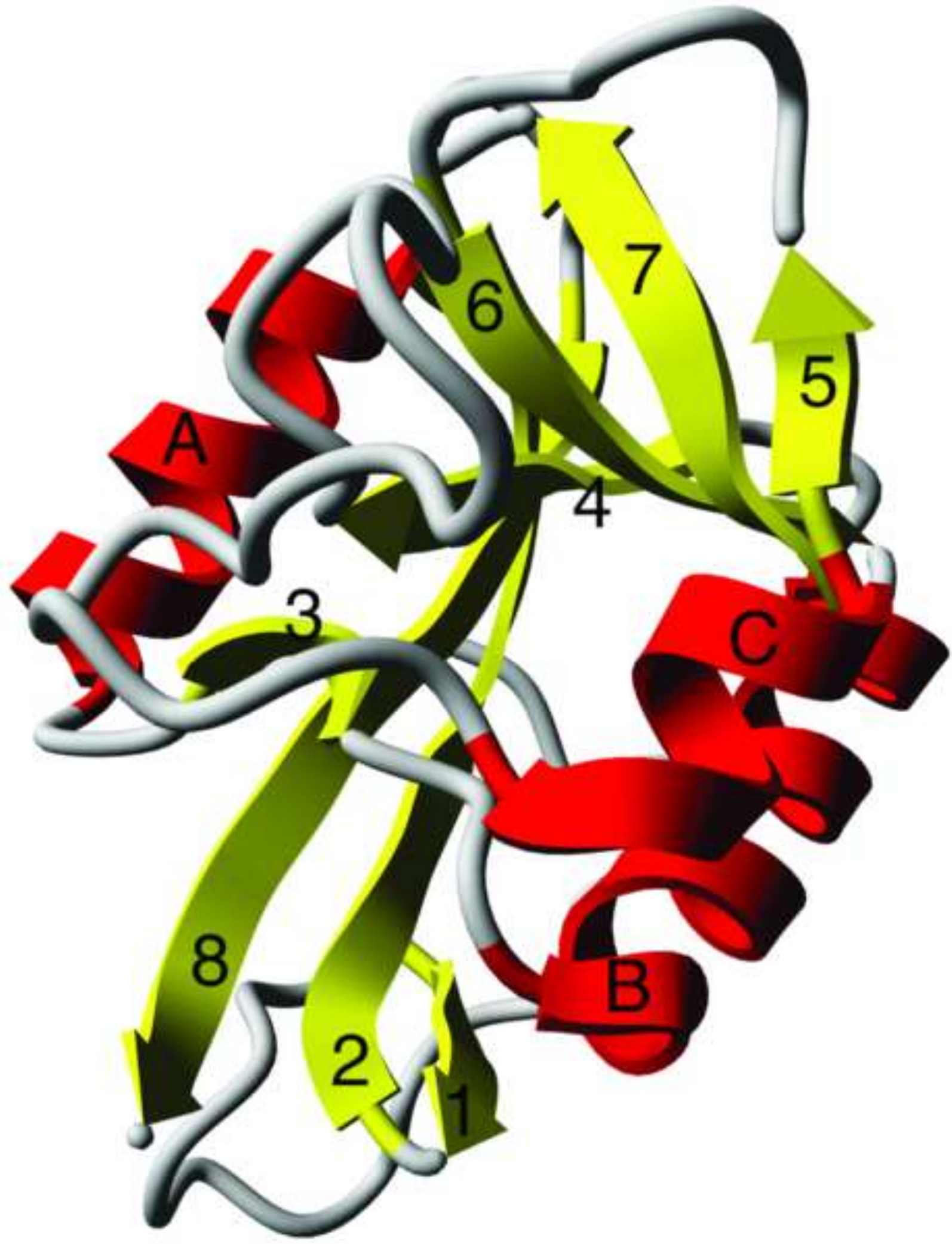



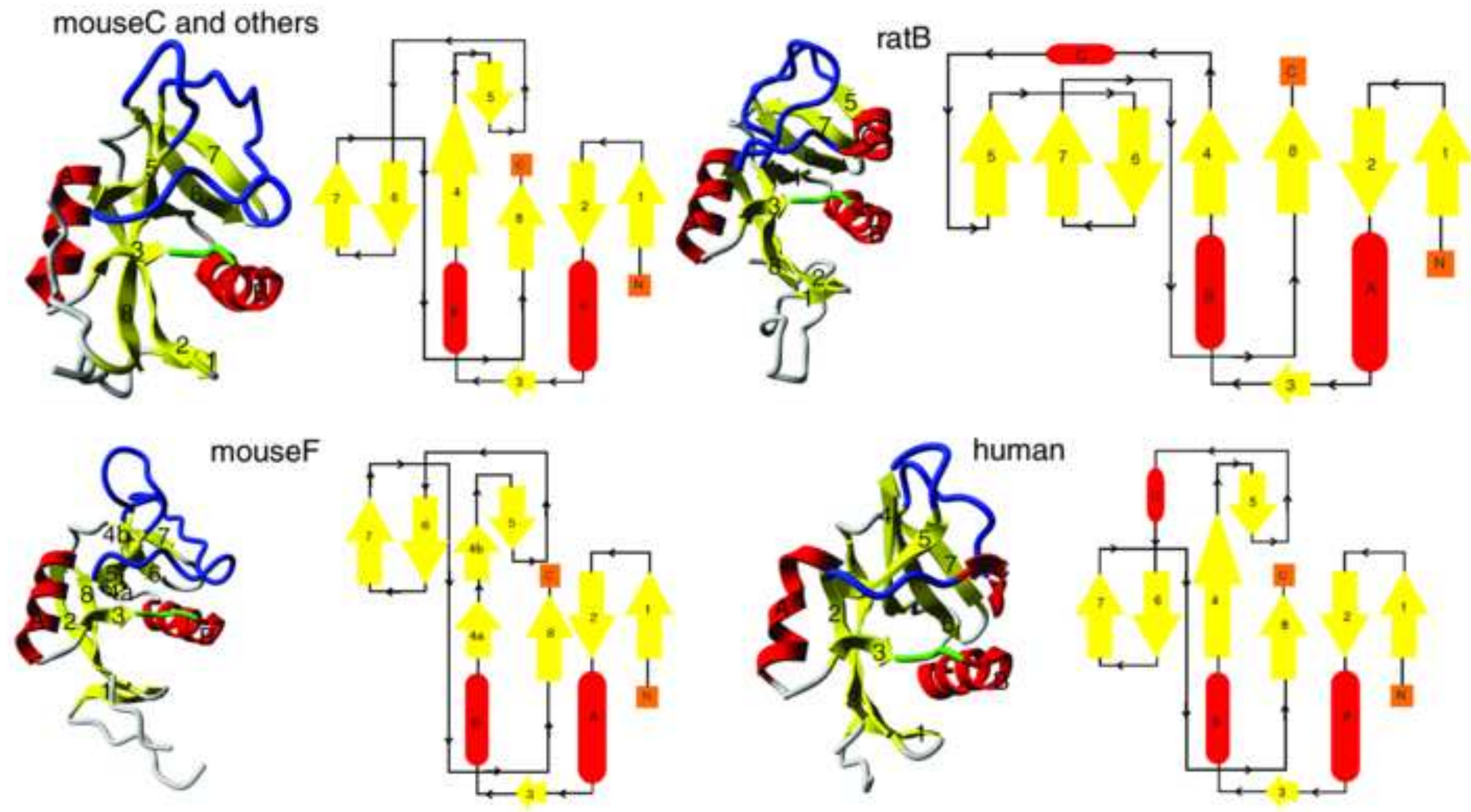


\section{Figure 11}

Click here to download high resolution image

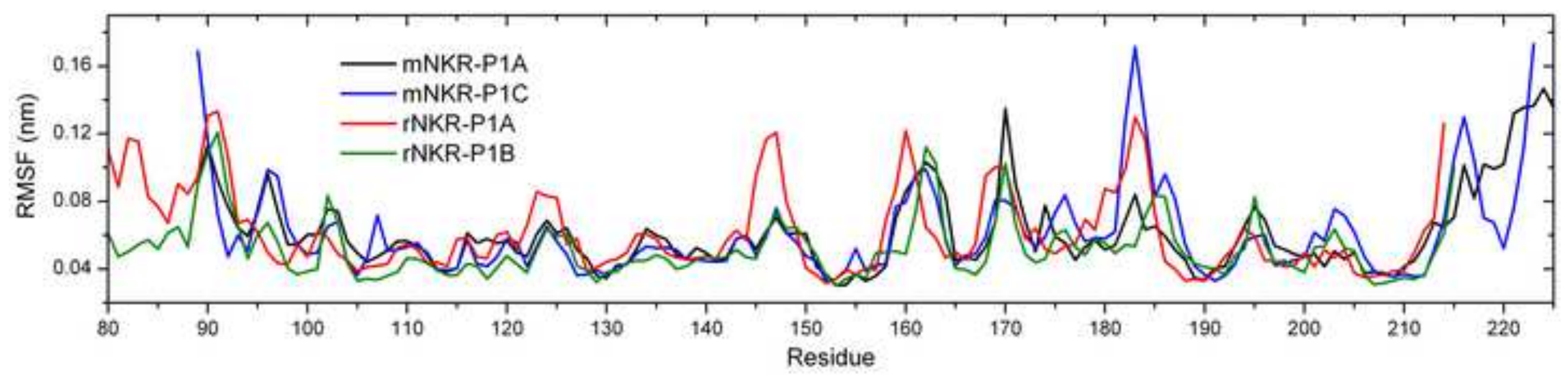

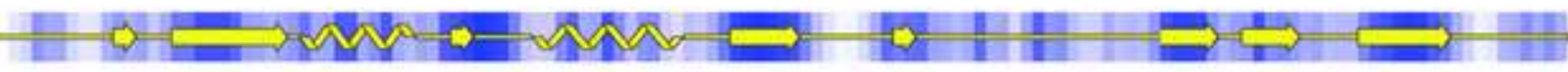


Figure 12

Click here to download high resolution image

Ita

$+\infty$,
III

+ Hatho
IVa

$-1+\cdots$

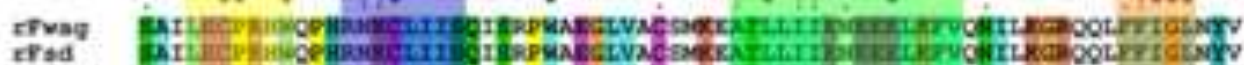

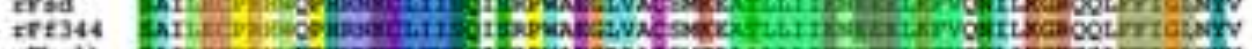

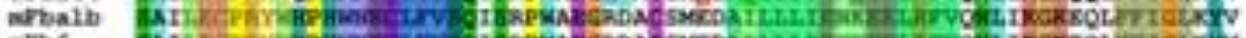

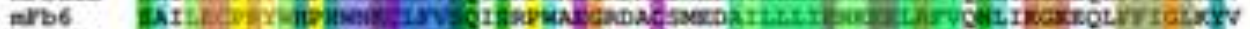

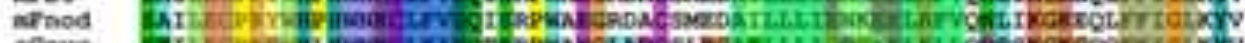

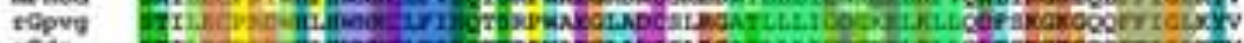

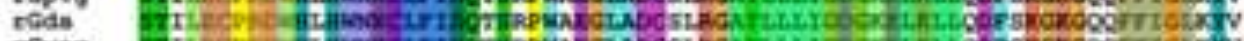

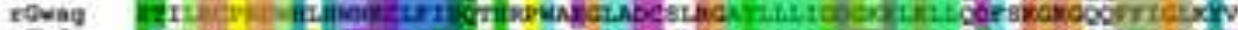
-u r.

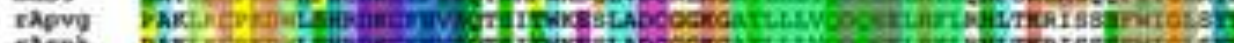
sarnk DAk,

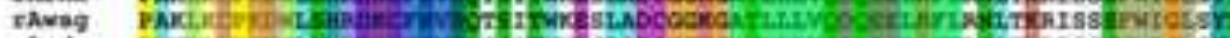

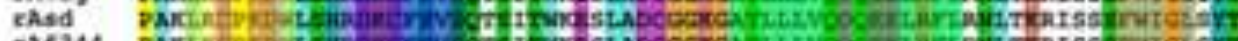

zaf344 PAKC,

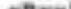

rnest4

rito

rllwag

EBbe

cliprig.

makaib

mast

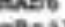

mabaity

meb6

nchall

nab6

nenod

hachin-p1

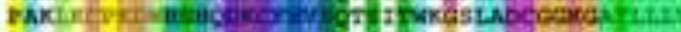

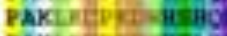

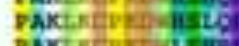

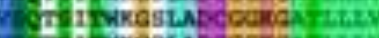

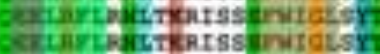

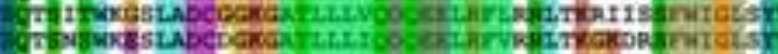

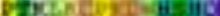

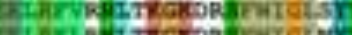

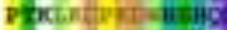

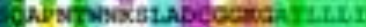

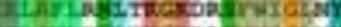

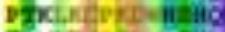

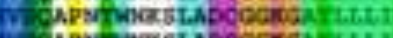

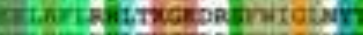

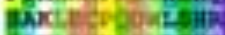

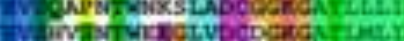

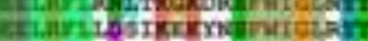

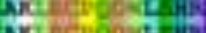

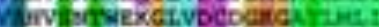

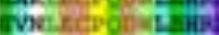

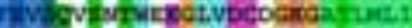

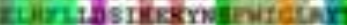

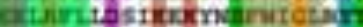

Ne

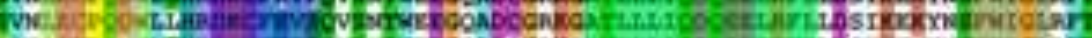

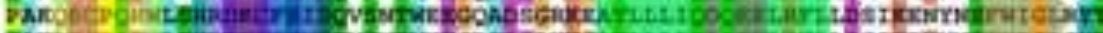

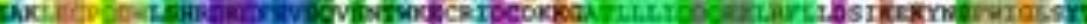

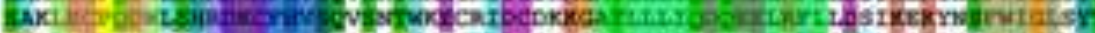
$\operatorname{CNCR} \rightarrow 1$

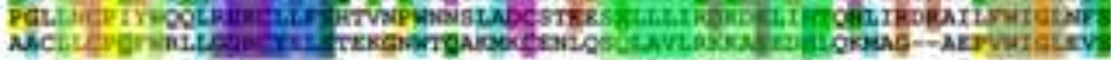

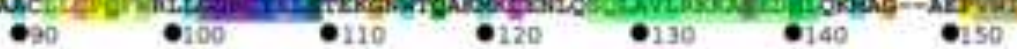

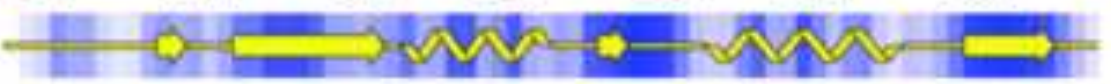

$1 \mathrm{Vh}$

H $\mathrm{b}$

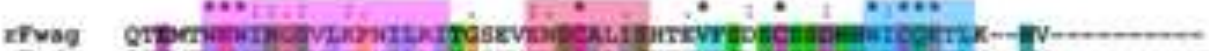

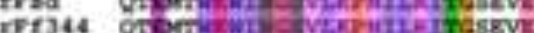

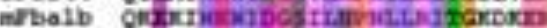

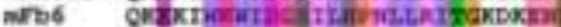

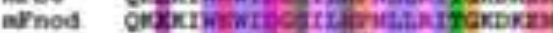

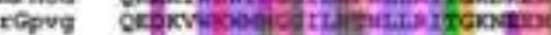

rods

soras

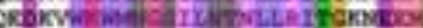

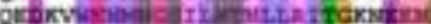

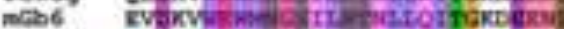

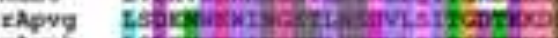

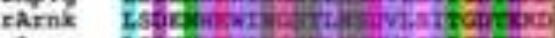

Exwag

tased

rarj44

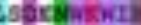

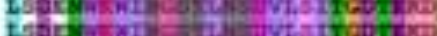

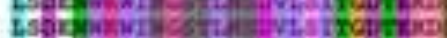

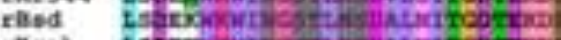

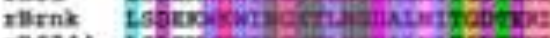

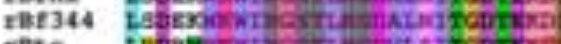

xilto

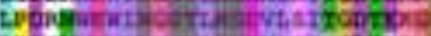

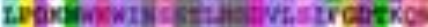

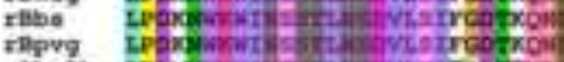

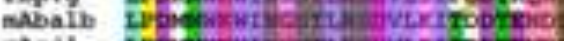

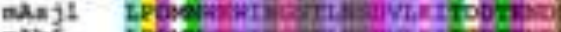

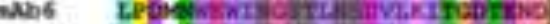

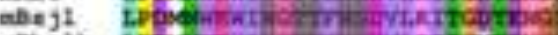

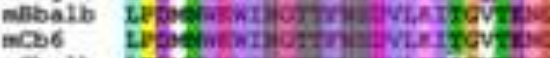

mctosth

nebe

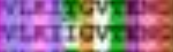

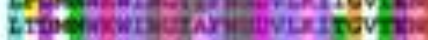

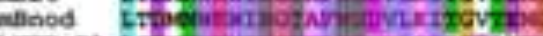

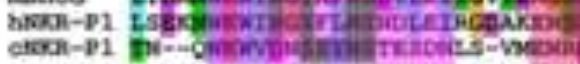

-1e0

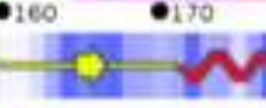

Qt.

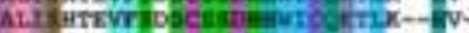

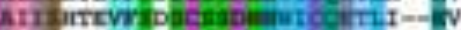

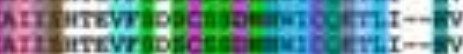

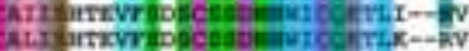

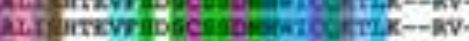

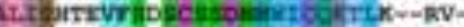

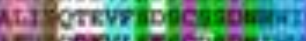

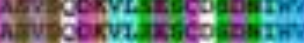

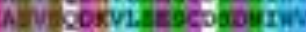

FH:- $\mathrm{F}$ -

Hix

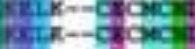

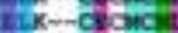

ritik-cracin

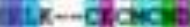

int $x-m$ - Sintent

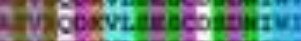

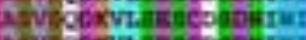

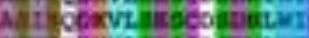

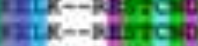

tix-menticion

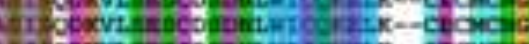

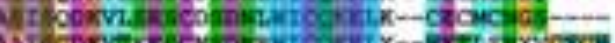

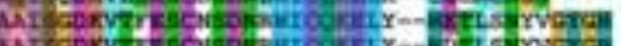

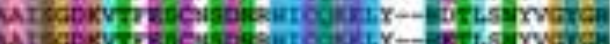

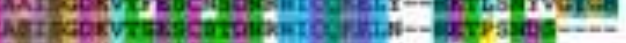

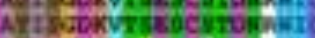

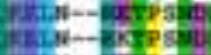

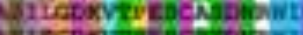

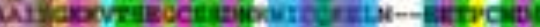

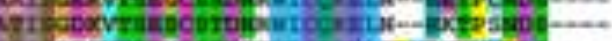
etron - 200

- 210

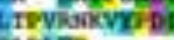

\begin{abstract}
-
\end{abstract}
200

e 220

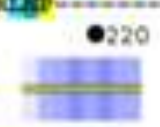

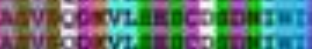

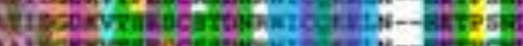

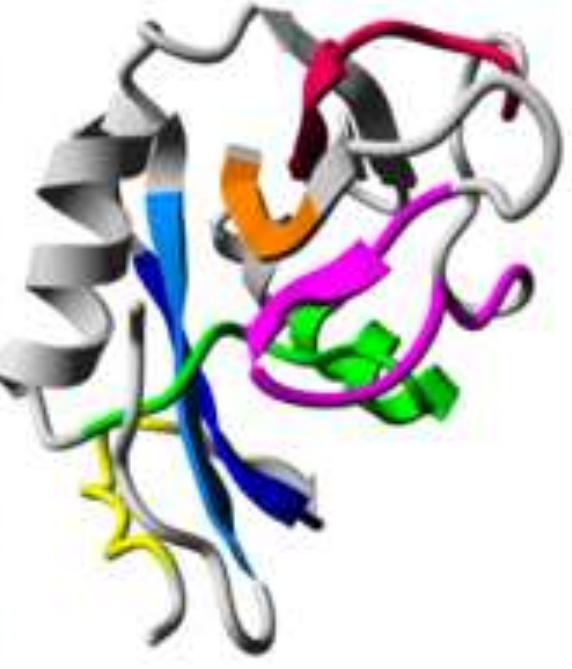


Click here to download high resolution image

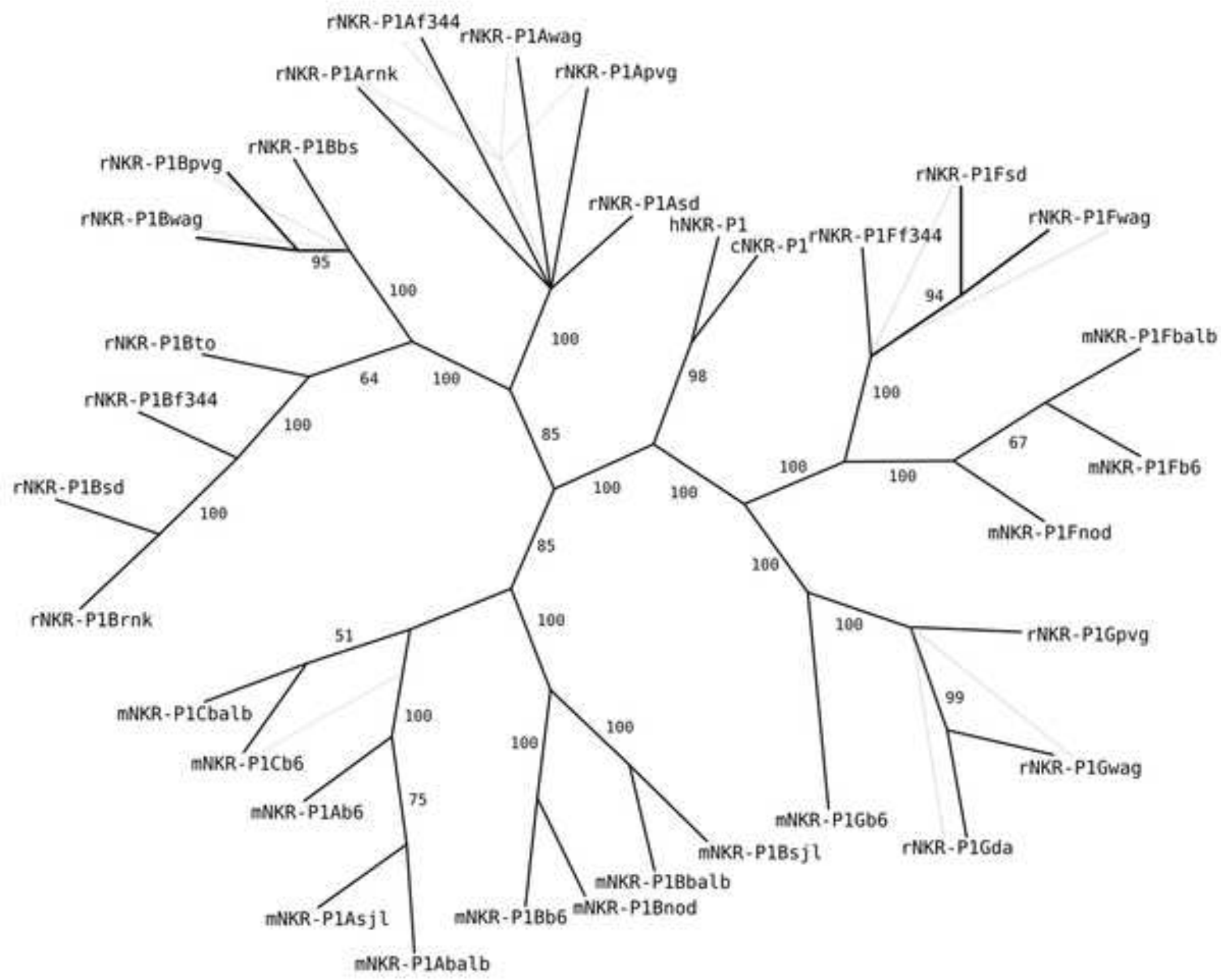

